\title{
Arquitectura, modernidad, modernización
}

\author{
Architecture, modernity, modernization \\ Arquitetura, modernidade, modernização
}

\author{
Jean-Louis Cohen \\ New York University (EE.UU.) \\ Institute of Fine Arts
}

Traductores:

\section{Andrés Ávila-Gómez}

Université Paris I Panthéon-Sorbonne (Francia)

\section{Diana Carolina Ruiz}

Université Paris IV Paris-Sorbonne (Francia)

Cohen, J-L. (2019). Arquitectura, modernidad, modernización. [Architecture, modernité, modernisation] (Andrés Avila-Gómez y Diana Carolina Ruiz, trads.) (original en francés, 2017). Revista de Arquitectura (Bogotá), 21(2), 126-142. doi: http://dx. doi.org/I0.14718/RevArq.2019.21.2.2539

\section{(a) $(1) \Theta$}

Jean-Louis Cohen

Arquitecto D.P.L.G (Diplomé par le gouvernement).

Doctor en Histoire de l'Art: École des Hautes Études en Sciences Sociales (EHESS). H.D.R. (Habilitación para dirigir tesis doctorales): École des Hautes Études en Sciences Sociales (EHESS).

Profesor invitado en el Collège de France (desde 2014).

Visiting Professor - School of Architecture: Princeton University (desde 2006).

Sheldon H. Solow Professor in the History of Architecture - Institute of Fine Arts: New York University (desde 1994).

https://www.college-de-france.fr/site/jean-louis-cohen/index.htm

(1) https://orcid.org/0000-0002-8420-3598

\section{Andrés Ávila-Gómez}

Arquitecto, Universidad de Los Andes (Colombia).

Magíster en Urbanismo, Universidad Nacional de Colombia.

Magíster en Ville, architecture, patrimoine, Université Paris 7 Diderot \& ÉNSA Paris-Val de Seine.

Doctorando en Histoire de l'Art, Université Paris I Panthéon-Sorbonne (École doctorale 44I).

(D) http://orcid.org/0000-0003-3883-2737

andresavigom@gmail.com

Diana Carolina Ruiz

Profesional en Langues Etrangères Appliquées, U. Paris IV Paris-Sorbonne.

Máster en Langues, littératures et civilisations étrangères, U. Paris IV Paris-Sorbonne.

(1D) http://orcid.org/0000-000I-5524-0456

http://dx.doi.org/10.14718/RevArq.2019.21.2.2539＜noBreak>karorr2002@gmail.com

\section{Resumen}

En el marco de una reflexión que tiene lugar actualmente en diversas instituciones francesas a propósito de la consolidación de la arquitectura como objeto de investigación científica -en un proceso que cumple casi medio siglo-, el presente texto interroga la idea de modernidad en arquitectura, y analiza discursos que han explicado la modernización de la sociedad a través de la arquitectura. Inicialmente, se describe el contexto que propició a principios de la década de los setenta la creación del CORDA: un organismo de carácter público que fomentó la investigación "por y para" la arquitectura. Por otro lado, como protagonista de dicho proceso, el autor del presente texto desarrolla (a partir de un conciso "autorretrato intelectual") la hipótesis acerca de la ruptura entre arquitectos e intelectuales que caracterizaba el panorama francés de la época -en evidente contraste con el caso italiano, por ejemplo-. Así, desde el análisis de episodios y casos puntuales que ilustran la diversidad de las relaciones que se han entretejido, por ejemplo, entre el arquitecto y el libro, los escritores y la arquitectura, o el edificio y la ciudad, se esclarecen algunos aspectos que en su conjunto (y privilegiando para ello una lectura transdisciplinar y transnacional) fortalecen la renovación de la historia de la arquitectura contemporánea como campo disciplinar.

Palabras clave: historia de la arquitectura; teoría de la arquitectura; enseñanza de la arquitectura; cultura arquitectónica; investigación en arquitectura.

\section{Abstract}

In the framework of an ongoing reflection in various French institutions regarding the consolidation of architecture as an object of scientific research-in a process that is almost half a century old-, this paper questions the idea of modernity in architecture, and analyzes discourses that have explained the modernization of society through architecture. Initially, it describes the context that led to the creation of the CORDA network in the early 1970s: a public organization that fostered research "by and for" architecture. On the other hand, as protagonist of this process, the author of the present text develops (based on a concise "intellectual self-portrait") a hypothesis about the rupture between architects and intellectuals, a characteristic of the French panorama of the period, in clear contrast with the Italian case, for example. Thus, based on the analysis of episodes and specific cases that illustrate the diversity of relationships that have existed, for example, between the architect and the book, writers and architecture, or the building and the city, the article elucidates some aspects that, as a whole (and privileging a transdisciplinary and transnational reading), strengthen the renewal of the history of contemporary architecture as a disciplinary field.

Keywords: History of architecture; theory of architecture; teaching of architecture; architectural culture; research in architecture.

\section{Resumo}

No âmbito de uma reflexão que acontece atualmente em diversas instituições francesas em virtude da consolidação da arquitetura como objeto de pesquisa científica — em um processo que já tem quase meio século —, este texto questiona a ideia de modernidade em arquitetura e analisa discursos que explicaram a modernização da sociedade por meio da arquitetura. Inicialmente, descreve-se o contexto que promoveu, no princípio da década dos 1970, a criação do CORDA: um organismo de caráter público que fomentou a pesquisa "por e para" a arquitetura. Por sua vez, como protagonista desse processo, o autor deste texto desenvolve, a partir de um conciso "autorretrato intelectual", a hipótese sobre a ruptura entre arquitetos e intelectuais que caracterizava o panorama francês da época - em evidente contraste com o caso italiano, por exemplo. Assim, a partir da análise de episódios e casos pontuais que ilustram a diversidade das relações que se entrelaçaram, por exemplo, entre o arquiteto e o livro, os escritores e a arquitetura, ou o edifício e a cidade, são esclarecidos alguns aspectos que, em seu conjunto (e privilegiando para isso uma leitura transdisciplinar e transnacional), fortalecem a renovação da história da arquitetura contemporânea como campo disciplinar.

Palavras-chave: história da arquitetura; teoria da arquitetura; ensino da arquitetura; cultura arquitetônica; pesquisa em arquitetura. 


\section{Introducción: la investigación en arquitectura en Francia ${ }^{1}$}

En Francia, desde hace medio siglo, la arquitectura ha sido objeto de una verdadera investigación científica: esta nueva situación se originó en el plano político con motivo del informe presentado en 1971 por encargo del Ministère des Affaires Culturelles (Ministerio de Asuntos Culturales), cuyo autor, André Lichnerowicz (1915-1998), fue titular de la cátedra de Física Matemática en el Collège de France entre 1952 y 1986 . Dicho informe, titulado La fonction architecturale, la recherche architecturale (La función arquitectónica y la investigación en arquitectura) condujo a la creación del Comité pour la recherche et le développement en architecture (Comité para la investigación y el desarrollo en arquitectura), más conocido luego simplemente como COR$\mathrm{DA}^{2}$. Aquel impulso generado en 1971 propició el surgimiento de un campo autónomo que aseguraba la formación de nuevos profesionales para la investigación, promoviendo la creación de laboratorios de investigación adscritos a las escuelas de arquitectura. De esta forma se gestó una auténtica investigación fundada científicamente, que llegaba a sumarse a la denominada "recherche patiente" (búsqueda paciente) -aqueIla desarrollada en el seno del atelier, centrada en el proyecto- reivindicada por Le Corbusier ${ }^{3}$ (1887-1965).

En Francia, la investigación en historia y en teorías de la arquitectura contribuyó de esta manera a una reconstrucción intelectual de la arquitectura ${ }^{4}$, paralelamente a otro tipo de trabajos basados en conocimientos cuantificables o modelizables -desarrollados inicialmente en campos más "confiables"-, como por ejemplo, aquellos que conciernen a las estructuras, la morfología o la geometría descriptiva, o incluso las matemáticas aplicadas a la arquitectura, así como también en el campo de las ciencias sociales aplicadas a los objetos construidos y a los procesos de concepción y de uso. Los arquitectos no fueron los únicos protagonistas de tal esfuerzo colectivo: sus trabajos se sumaron a los realizados por historiadores del arte, sociólogos, geógrafos y urbanistas desde sus propios campos disciplinares e institucionales. Los saberes establecidos en el ámbito científico de la arquitectura eran a menudo

1 El presente texto es la traducción del francés del artículo Architecture, modernité, modernisation, del historiador de la arquitectura Jean-Louis Cohen, publicado en 2017 por el Collège de France. Dicho texto constituye la conferencia inaugural con la cual el profesor Cohen abrió en mayo de 2014 su catedra anual "Architecture et forme urbaine" como profesor invitado por el Collège de France.

Texto original en francés disponible en: Jean-Louis Cohen (2017). Architecture, modernité, modernisation, Paris, Collège de France/Fayard, coll. "Leçons inaugurales", 265; édition numérique: Paris, Collège de France, 2017, https://books. openedition.org/cdf/4864 (texte intégral en accès ouvert).

2 Sobre las políticas oficiales desarrolladas en esta época, ver L'État et l'architecture: 1958-1981: une politique publique? (Lengereau, 2001)

3 Ver L'Atelier de la recherche patiente (Le Corbusier, 1960).

4 Ver Les Architectes et Mai 68 (Violeau, 2005). asimilados por historiadores, sociólogos o antropólogos, sin que de aquellas prolíficas investigaciones emergiera algún tipo de teoría global de la disciplina, aun cuando personajes como Philippe Boudon ${ }^{5}$ (1941) se empeñaron en desarrollar de manera aislada algunos conceptos específicos del campo de la arquitectura, luego de haber estudiado juiciosamente la recepción de intervenciones modernas. $Y$ es importante subrayarlo: difícilmente una teoría en tal dirección sea posible hoy en día.

Como joven profesor e investigador, y más tarde en calidad de responsable científico del CORDA, estuve presente en el corazón de aquel proceso de renovación descrito, fui testigo privilegiado de la fecundidad de dicho organismo: es un hecho comprobado que el CORDA afianzó la existencia de un entorno apto para la investigación, y, lo que es más importante, permitió corroborar que además de la concepción de espacios y de formas, la arquitectura podía también producir sus propios discursos en la medida en que la disciplina fuera capaz de formar intelectuales "orgánicos" -según el concepto definido por Antonio Gramsci (1891-1937)-, situación que no se había presentado hasta entonces en la Francia del siglo $X X^{6}$. La experiencia específica en investigación resultó determinante para los profesores en quienes se depositó la ardua tarea de crear las nuevas escuelas de arquitectura en el momento en el que esta pudo por fin escapar del rígido marco impuesto por la École des Beaux-Arts (Ensba), en cuyo seno había sido enseñada a lo largo de los 150 años precedentes. La investigación se convirtió en un aspecto igualmente determinante para aquellos jóvenes profesionales que, como Christian de Portzamparc (1944-), Christian Devillers (1946-) o Patrick Berger (1947-) estuvieron absolutamente comprometidos con los programas en boga durante los años setenta ${ }^{7}$. Al mismo tiempo, muchos de los arquitectos cuyos proyectos permitieron superar un modernismo extenuado y un posmodernismo fatigante, trazaron inicialmente su estrategia personal a través del texto escrito: tal fue el caso en Europa, de figuras tan disímiles como Rafael Moneo (1937-) o Rem Koolhaas (1944-), por citar solamente dos de los ejemplos más estimulantes ${ }^{8}$.

\section{Un itinerario personal}

Bajo la forma de una cierta rebelión, mi interés por la arquitectura se manifestó inicialmente en reacción al culto a las ciencias que dominaba mi entorno familiar poblado de químicos,

5 Ver Pessac de Le Corbusier (Boudon, 1969); Introduction à I'architecturologie (Boudon, 1992)

6 Ver La Coupure entre architectes et intellectuels, ou les enseignements de l'italophilie (Cohen, 1984, 2015).

7 Ver Le Creusot: naissance et développement d'une ville industrielle, 1782-1914 (Devillers, 1981); también Panauti, une ville au Népal (Barré, Berger et al., 1981).

8 Ver La solitudine degli edifici e altri scritti (Moneo, 2004); New York délire: un manifeste rétroactif pour Manhattan (Koolhaas, 1978) 
de físicos y de biólogos; aunque dicha rebelión se veía temperada en parte debido a la admiración hacia mi abuelo lingüista, Marcel Cohen (1884-1974). Bajo otras formas de resistencia me enfrentaría más tarde al gremio de los arquitectos -al menos en lo que respecta a su configuración francesa más arraigada e inmóvil-, sobre todo tras descubrir de primera mano en Estados Unidos las realizaciones de los norteamericanos, como también en Italia aquellas de los italianos, y a través de Alemania las de los rusos -fundamentalmente lo hecho durante los años veinte, vale la pena precisarlo, en vista del desolador panorama de la Unión Soviética a causa del estancamiento de la era brezhneviana-. Mientras aquellos arquitectos del siglo XX que habían sido determinantes hasta entonces con su repertorio de edificios fascinantes -Frank Lloyd Wright o Le Corbusier, por ejemplo-, habían dejado para mi generación un discurso rimbombante e improductivo, algunas otras figuras paternales -o más bien avunculares- menos conocidas se encargaron de promover puntos de inflexión decisivos.

Guardo en mi mente las conferencias semanales que impartía en el Conservatoire National des Arts et Métiers (CNAM), el genial constructor Jean Prouvé ${ }^{9}$ (1901-1984), trazando en el tablero maravillas con la punta de una tiza: edificios que parecían inspirados en automóviles o en aviones, durante sesiones que merecen ser llamadas verdaderas "performances" (Figura 1). No obstante, Prouvé se encontraba demasiado aislado, una figura optimista en medio de un entorno profesional salpicado por el cinismo con el cual se había encarado desde la profesión de arquitecto, tanto la política estatal de los grands ensembles (grandes conjuntos de vivienda social), como la política de promoción privada. Desde Filadelfia, la voz de Louis Kahn (1901-1974) constituía en aquel momento la única verdaderamente perceptible, retumbando desde aquel otro continente que yo no conocería sino algunos años

9 Ver "Des mains qui voient: les cours du CNAM (1958-1971)" (Cohen, 2005, pp. 50-55). más tarde, tal y como lo habían hecho en los años sesenta algunos de los arquitectos franceses cuya trayectoria me inspiraba ${ }^{10}$.

La célebre antología preparada en 1965 por Françoise Choay (1925-), L'Urbanisme, utopies et réalités (Figura 2) significó para mí un descubrimiento apasionante que incitaba a la lectura arborescente de las teorías enunciadas desde finales del siglo XIX; tanto como lo fue también Ville et révolution (Figura 3), texto con el cual Anatole Kopp (1915-1990) develaba en 1967 los proyectos y las ilusiones de la vanguardia rusa, empujándome a visitar aquel país para ver de cerca los vestigios de aquellas experiencias y para conocer los últimos protagonistas de aquella época.

Por otro lado, tras la lectura de Théorie du nuage (1972), asistí regularmente al seminario dictado por Hubert Damisch (1928-2017) -que dio origen años más tarde a Skyline-. La ville Narcisse (1996), en el cual exponía los objetos teóricos de la arquitectura, y sus vues topiques de los fenómenos urbanos; aquel seminario se convirtió para mí en un remanso fecundo en el cual pude refugiarme y sentirme a salvo de aquellos discursos emanados de la sociología urbana de los años setenta, que ya encontraba personalmente demasiado estériles.

Por aquella época, en Venecia, Manfredo Tafuri (1935-1994) había fundado un departamento de Historia de la Arquitectura en cuyo seno tomaba forma un tipo de investigación colectiva -iluminada por un abierto marxismo y por un compromiso crítico frente a las historias canónicas- a partir de la cual se vislumbraba un panorama de investigaciones intelectualmente consistentes. Apropiándose de los conceptos de la lingüística estructural, Tafuri se apoyaba en los textos de la Escuela de Frankfurt (Frankfurter Schule) ya tra-

10 Como, por ejemplo, Bernard Huet, cuya trayectoria ha sido estudiada por Juliette Pommier en su tesis doctoral titulada Vers une architecture urbaine, la trajectoire de Bernard Huet (2010).

(1) Figura 1. Jean Prouvé dictando uno de sus cursos en el Conservatoire National des Arts et Métiers (CNAM) (hacia 1967)

Fuente: Bibliothèque Kandisnky@. Centre Pompidou MNAM/CCI.

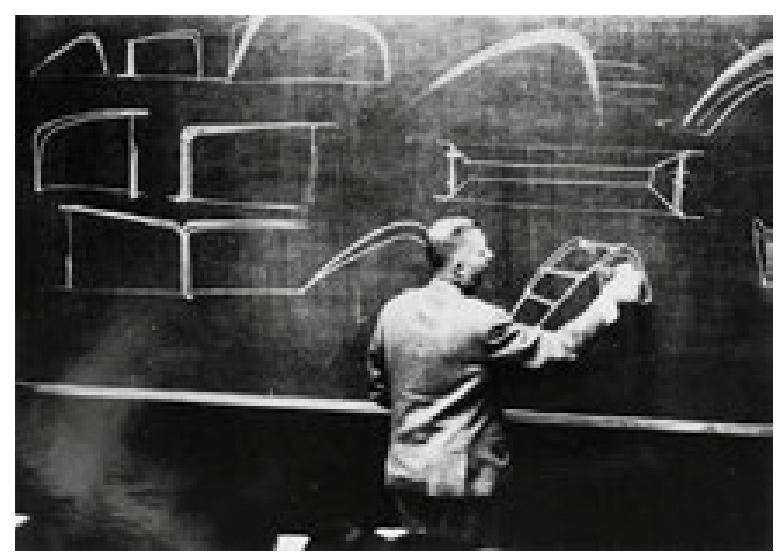

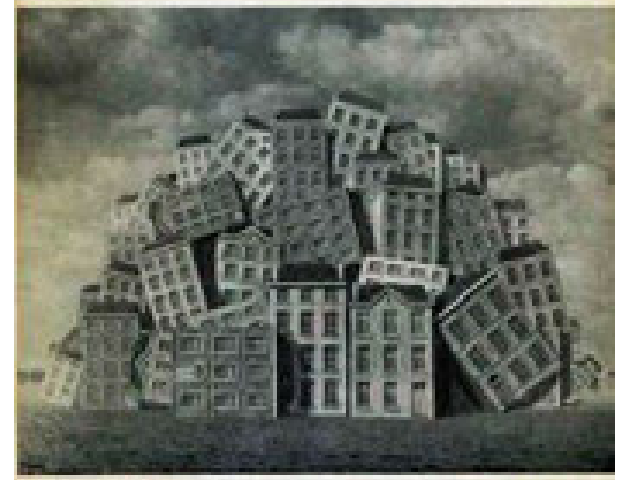

aux Éditions du Seuil, Paris
\& Figura 2. Portada de L'Urbanisme, utopies et réalités Fuente: Françoise Choay (1925).

(v) Figura 3. Portada de Ville et révolution Fuente: Anatole Kopp (1967).

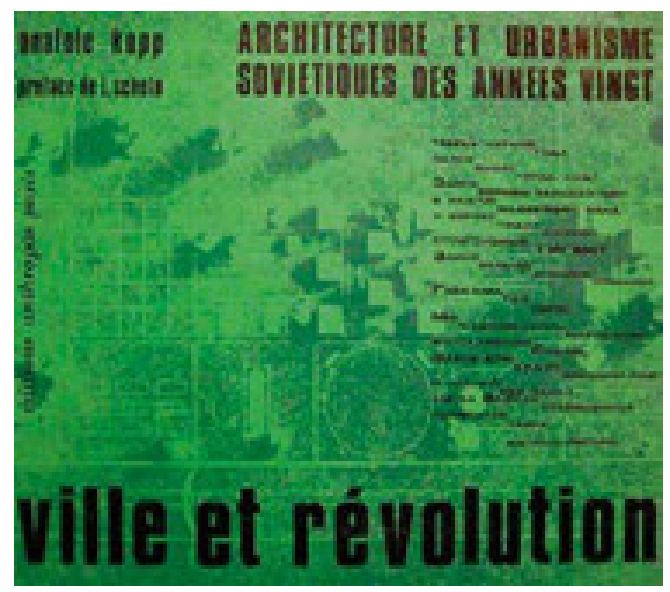


ducidos al italiano $y$, en todo, caso varios años antes de serlo al francés; por aquella vía pude leer por primera vez, y en la lengua de Dante, los textos más importantes de Theodor Adorno (1903-1969) y de Walter Benjamin (1892-1940). Sin duda, el enfoque de Tafuri sobre la arquitectura contemporánea se convirtió para mí en una especie de brújula, más allá de la polémica de sus excesos condensados en su célebre aforismo: "No existe la crítica, únicamente la historia"11.

Al igual que como ocurría con Tafuri, otros discursos movilizadores poblaban aquel archipiélago de discursos desde los cuales tanto autores como investigadores se alistaban como náufragos que preparan sus embarcaciones para regresar a tierra firme. En aquel paisaje, los continentes formados por la estimulante obra de algunos teóricos parisinos resultaban estimulantes, especialmente si se trataba de aquellos discursos formulados a partir de memorables análisis sobre la arquitectura, como sucedió en 1975 con Surveiller et punir (Vigilar y castigar) en el cual Michel Foucault (1926-1984) examinó aquellos lugares de reclusión definidos por él mismo en 1967 como heterotopías (los espacios "otros"), en el marco de una conferencia pronunciada en el Cercle d'études architecturales $^{12}$-uno de los cenáculos más respetados del momento-. Ya en 1973, Utopiques, jeux d'espace de Louis Marin (1931-1992) había contribuido a repensar la utopía, sin ingenuidad o reduccionismo de ninguna clase, una utopía por lo demás protagonista de buena parte de los discursos en boga de aquellos años. Otra de las posibles escapatorias que podía conducirnos por fuera de los trajinados senderos de la historia del arte, o del campo aún hostil e inexplorado de la historia de la arquitectura, para acercarnos a un verdadero análisis de las formas, la constituye aquella ruta abierta en 1957 por Roland Barthes (1915-1980) con Mythologies -ruta prolongada en 1973 con Le plaisir du texte (El placer del texto)-. En últimas, descubrimos en aquella época que era definitivamente en la teoría en donde encontraríamos los discursos más provocadores, y no tanto en la historia del arte, como se había pensado.

Extremadamente curioso acerca de las relaciones de dependencia que parecían haberse establecido entre diversos grupos de arquitectos franceses con respecto a Italia, me vi rápidamente inmerso en el estudio del fenómeno de la italofilia. Dicho fenómeno apareció ante mis ojos como revelador de una "ruptura" entre arquitectos e intelectuales, característica del panorama francés de la época, mientras que, por el contrario en Italia los arquitectos habían sido capaces de entablar nexos fecundos con escritores, filósofos e historiadores ${ }^{13}$ : así ocurrió, por ejem-

11 Ver la entrevista de Manfredo Tafuri concedida a Richard Ingersoll en: "Il progetto storico di Manfredo Tafuri" (Casabella, 1995).

$12 \mathrm{El}$ texto de la conferencia pronunciada el 14 de marzo de 1967 fue publicado en el núm. 5 de Architecture, mouvement, continuité, en octubre 1984, bajo el título "Des espaces autres".

13 Ver La coupure entre architectes et intellectuels (Cohen, 1984, 2015). plo, con Vittorio Gregotti (1927-) tan cercano a Umberto Eco (1932-2016) y al Gruppo '63; con Giancarlo de Carlo (1919-2005), amigo del escritor Elio Vittorini (1908-1966); o con la relación entre Ernesto Nathan Rogers (1909-1969) y el filósofo husserliano Enzo Paci (1911-1976).

Cuestionar la modernidad en la arquitectura, tal y como Rem Koolhaas invitaba a hacerlo a los participantes en la Bienal de Venecia en 2014, no consiste solamente en inventariar los nuevos elementos presentes en el léxico de la arquitectura, o en identificar los nuevos modos de composición y de agrupación de las formas imaginadas -siguiendo un enfoque sintáctico, al recurrir al modelo lingüístico-, desde la formación de lo que usualmente se conoce como el Movimiento Moderno asociado siempre de manera trivial a las figuras de Wright, Le Corbusier (Figura 4), Gropius o Mies van der Rohe.

Como lo ha señalado Antoine Compagnon (1950-) en Les cinq paradoxes de la modernité (1990) (Las cinco paradojas de la modernidad), la modernidad puede ser reconducida hacia una celebración de lo nuevo y hacia un culto del futuro: dos actitudes habituales desde mediados del siglo XIX entre los arquitectos más radicales, como en el caso del visionario Hector Horeau (1801-1872) (Figura 5), contemporáneo de Baudelaire -de quien difícilmente podríamos encontrar homólogos en el ámbito de la arquitectura-.

En el ámbito de la arquitectura, el fenómeno de la modernidad resultaba más complejo que en el arte o en la literatura: las formas y los espacios que la constituyen se relacionan con un pensamiento y una estética en clara ruptura con el historicismo del siglo XIX, que se ajustan a los programas anunciados por el sistema globalizador propio de una modernización que afecta la producción, el consumo y los territorios, es decir, el conjunto de la sociedad. La sincronía entre estos dos ciclos de transformación, uno de ellos estético, y el otro económico y técnico -proveyendo este último sus programas al anterior- no constituye una regla absoluta, como sí sucede usualmente en el caso de la literatura: Baudelaire aborrecía la industria (Compagnon, 1990, p. 28). Por ello, algunos programas modernos pueden ser interpretados con formas tradicionalistas o nostálgicas, como sucede en las obras de Auguste Perret (Figuras 6 y 7), en las cuales se reconoce un espíritu clásico de inspiración griega ${ }^{14}$; mientras que otras formas modernas emergieron al interior de estructuras sociales marcadas por lentas transformaciones, como sucedió en Brasil. Asimismo, una tentación extrema de las vanguardias fue justamente la de forzar la modernización de la vida cotidiana, encerrándola entre formas radicalmente nuevas -como sucedió con el constructivismo ruso-

Un caso típico de sincronía entre modernidad y modernización es sin duda el de la Maison

14 Ver Christian Freigang, "Sources et prémices de l'édifice théorique" (2002, pp. 156-159) 
du Peuple construida en 1939 en Clichy (Figura 8) (comuna situada al noroccidente de París) por Eugène Beaudouin (1898-1983), Marcel Lods (1891-1978), Vladimir Bodiansky (18941966) y Jean Prouvé. La estructura metálica ligera y transformable alberga a la vez un supermercado, una sala de cine en un entrepiso retráctil y las oficinas de las asociaciones locales (Figura 9). Aparecía así un nuevo tipo de equipamiento colectivo en el cual los autores del Centre Pompidou encontraron una de sus inspiraciones treinta años más tarde ${ }^{15}$.

En los años cincuenta, la concepción de los dispositivos del conjunto habitacional de Djenan el-Hassan, por el arquitecto Roland Simounet (1927-1996), se basó en la observación sociológica de los barrios de bidonvilles (tugurios o chabolas), así como en la observación etnográfica de las ciudades del sur de Argelia. Las formas de agrupación y las bóvedas empleadas en dicho proyecto guardan una innegable semejanza formal con dos proyectos corbusieranos: el proyecto de las casas Jaoul (1951) en Neuilly-sur-Seine, y el proyecto Roq (1949) en Roquebrune-Cap-Martin; aunque en el caso de Djenan el-Hassan, se trataba de un proyecto surgido del esfuerzo desesperado de una Francia colonial vacilante que buscaba responder -ya tardíamente- a las expectativas de una población musulmana.

Por aquella misma época encontramos la reconstrucción del muelle del Vieux-Port de Marseille (Puerto Viejo de Marsella) en la cual

15 Ver Bruno Reichlin, "Maison du peuple at Clichy, a masterpiece of 'synthetic' functionalism?" (Daidalos, 1985).
Fernand Pouillon (1912-1986) recurrió a la forma tradicional de la arcada construida a partir de una mampostería estructural -aunque complementada con placas en concreto-. El proyecto de Pouillon, aunque conservador en muchos aspectos, constituía por su volumetría y por la estricta racionalización implementada en su construcción, un ejemplo emblemático del programa de modernización ejecutado tras la Segunda Guerra Mundial.

Recordemos cómo en 1928, en Bauen in Frankreich, Eisen, Eisenbeton ${ }^{16}$ (Figura 10) -su primer libro consagrado a la arquitectura moderna-, el historiador suizo del arte Sigfried Giedion (1888-1968) calificaba el "temperamento de los constructores" como un elemento característico de la escena nacional francesa: para el autor, "ce goût de la France pour la construction est tout aussi nécessaire à la nouvelle architecture que les dispositions montrées par l'Amérique pour l'organisation, ou que la parfaite formation que la Hollande donne à ses artisans"17 (Giedion, 1928 [2000], p. 69). El análisis de Giedion se apoyaba tanto en su conocimiento privilegiado de la Francia de los años posteriores a la Primera Guerra Mundial -en donde había podido visitar tantas y tantas obras-, como en su amplio conocimiento

16 Ver la traducción francesa publicada en 2000: Construire en France, en fer, en béton (traducción del alemán al francés realizada por Guy Ballangé, revisada por Jean-Louis Cohen).

17 “...el evidente gusto que se manifiesta en Francia por la construcción era absolutamente necesario para una nueva arquitectura; como lo fue también en los Estados Unidos la preocupación por todo lo que concierne la organización de esta; o como lo fue en Holanda, la estupenda formación ofrecida a los artesanos de la construcción".

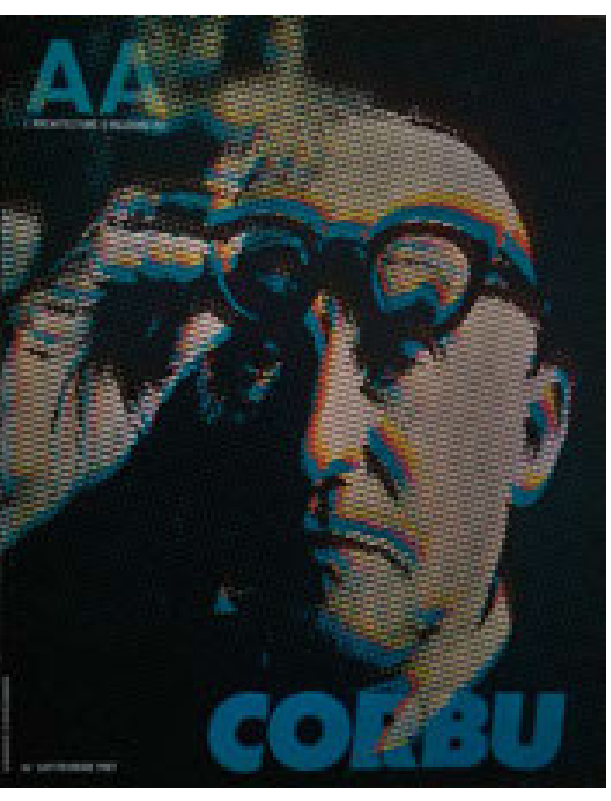

(A) Figura 4. Cubierta del número especial ( $\left.{ }^{\circ} 249\right)$ de L'Architecture d'aujourd'hui, dedicado en febrero de 1987 a Le Corbusier

Fuente: L'Architecture

d'aujourd'hui.

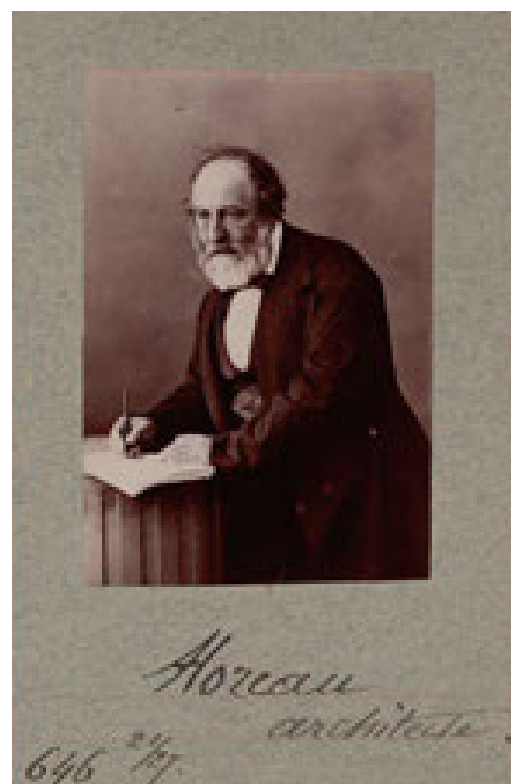

(A) (A) Figura 5. El arquitecto francés Hector Horeau (1801-1872), imagen sin fecha (foto: Atelier Nadar)

Fuente: Gallica - Bibliothèque nationale de France* ${ }^{*}$, Département Estampes et photographie, FT 4-NA235 (2). Dominio público.

* Horeau, architecte: Atelier Nadar, en https://gallica.bnf.fr/ark:/12148/ btv1b53065539z.r $=$ hector $\% 20$ horeau? rk $=42918 ; 4$

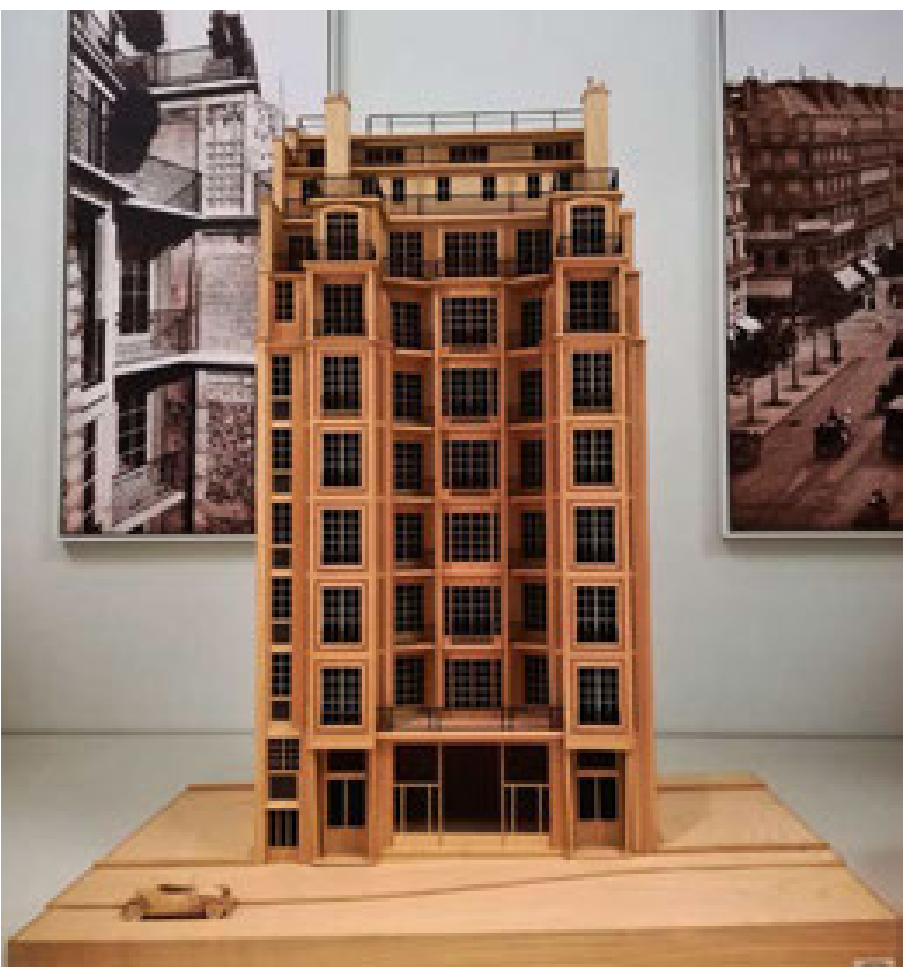

(A) Figura 6. Maqueta del edificio de viviendas de la rue Franklin en París (construido entre 1903 y 1904 por los hermanos Auguste y Gustave Perret) exhibida en la "Galerie d'architecture moderne et contemporaine" de la Cité de l'architecture et du patrimoine Fuente: Andrés Ávila Gómez (2018). CC BY-NC-ND. 
acerca de los ingenieros del siglo XIX descubiertos gracias a sus visitas constantes a las bibliotecas parisinas.

Que un análisis precoz como Bauen in Frankreich, Eisen, Eisenbeton (Construir en Francia, construir en hierro, construir en hormigón) haya sido publicado en Alemania, de la misma forma en que veinte años atrás lo había sido un texto como Eisenbauten: ihre Geschichte und Æsthetik (1907) (Figura 11) (Construcciones en hierro: su historia y su estética) de Alfred Gotthold Meyer (1864-1904), primer estudio consagrado a la estética de las construcciones metálicas y cuyo referente era abrumadoramente francés, confirma la inanidad de una historia estrictamente "francesa" sobre la propia arquitectura "francesa".

Desde el punto de vista empírico, esta reflexión debe ampliarse a un marco mucho más vasto que incluya igualmente los aportes hechos en Francia por arquitectos venidos de otras tierras -como en el caso del Centre Pompidou de Renzo Piano (1937-), Richard Rogers (1933-) y Ove Arup (1895-1988); y de los edificios de la Unesco (Figura 12) de Marcel Breuer (19021981), Pier-Luigi Nervi (1891-1979) y Bernard Zehrfuss (1911-1996)-, así como los proyectos franceses realizados en otras partes del mundo, y no solo en las colonias y protectorados franceses que obtuvieron su independencia en los años sesenta ${ }^{18}$.

Ahora bien, confrontar la dimensión nacional con un internacionalismo uniformizador, tal y como lo hicieron durante los años treinta algunos críticos reaccionarios como los arquitectos Gustave Umbdenstock (1866-1940) o Alexander von Senger (1880-1968), sería en todo caso no menos simplificador. Aunque existió un estilo "internacional" como aquel codificado por los comisarios de la primera exposición de arquitectura realizada por el Museum of Modern Art de Nueva York (MoMA) en 1932 ${ }^{19}$, no se trataba, sin embargo, del mismo estilo que parecían definir las obras de Gropius, Mies van der Rohe o Le Corbusier. Más cercano a un estilo "internacional" parecía estar aquel elaborado en el seno de la École des Beaux-Arts de París casi un siglo antes de la muestra en el MoMA: aquel fue un verdadero sistema de pensamiento y de dibujo que reivindicaba el eclecticismo como forma de liberté d'écriture, lo que resultaba particularmente eficaz para componer la espacialidad de bancos, de estaciones de tren -al menos a su espacio interior-, de óperas y de parlamentos, e incluso de rascacielos ${ }^{20}$.

Como en una especie de ballet, las hegemonías se fueron sucediendo -e integrándose en no pocas ocasiones- en tanto el modelo impuesto

18 Ver L'Architecture au XXe siècle en France; modernité et continuité (Cohen, 2014).

19 Ver The International Style: Architecture since 1922 (Hitchcock y Johnson, 1932)

20 Ver el libro ya clásico: The Architecture of the École des beaux-arts (Drexler, 1977). Sobre el método de composición beauxartiano, ver Comprendre l'éclectisme (Epron, 1997). por la École des Beaux-Arts había entrado en crisis $^{21}$. Las arquitecturas concebidas en Francia -tanto las construidas como aquellas jamás realizadas- y aquellas concebidas en otras latitudes, pero construidas en territorio francés, expresaron ideas y problemáticas de los más diversos orígenes. En el ámbito de la vivienda, la idealización del home británico cedió su lugar a una idealización de las villas californianas, mientras que las ciudades jardín, inspiradas en los ejemplos pioneros británicos, evolucionaron ante el contacto con las Siedlungen de Berlín y de Fráncfort. Después de la Segunda Guerra, las texturas de la arquitectura finlandesa, las curvas emblemáticas de la arquitectura brasilera y la apertura de la arquitectura californiana hacia el paisaje consiguieron oponer una escritura más poética a aquella tendencia absolutamente racional difun-
21 Ver "Le culture della modernizzazione: il balletto delle ege- monie" (Cohen, 2004, pp. 21-31); "Modernité et internatio- nalisation" (Cohen, 2014, pp. 37-43)

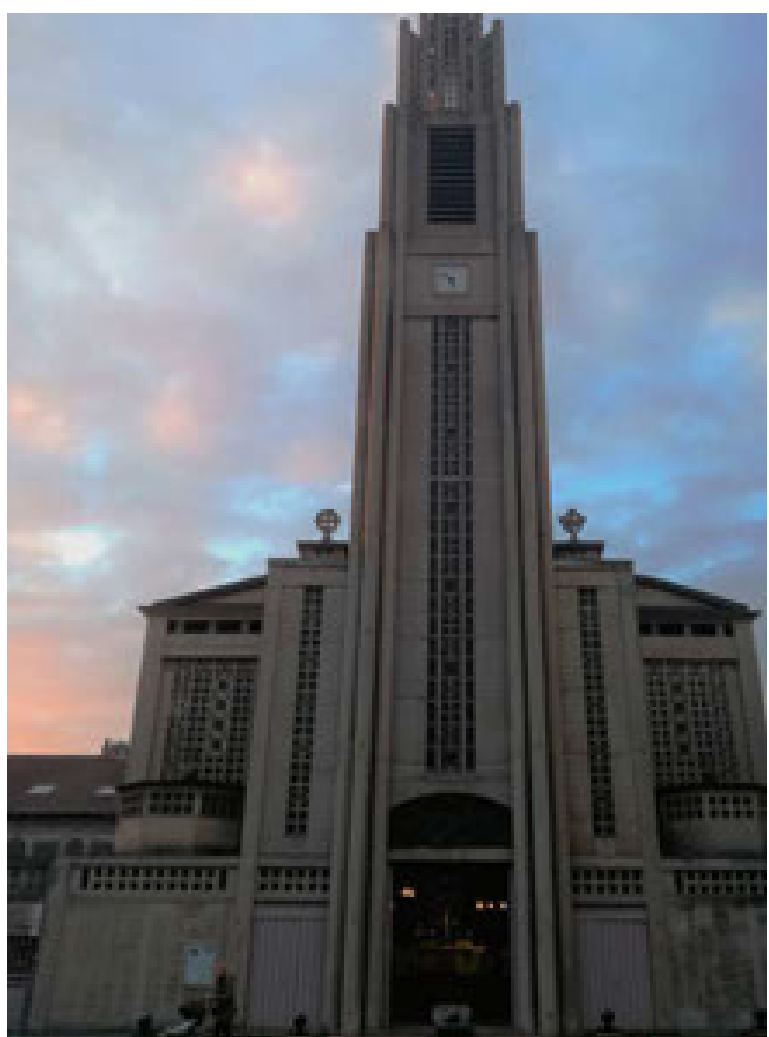

\&igura 7. Vista actual de la fachada de la iglesia de Notre-Dame du Raincy (construida entre 1922 y 1923 por los hermanos Auguste y Gustave Perret) en la periferia nororiental de París

Fuente: Andrés Ávila Gómez (2018). CC BY-NC-ND.

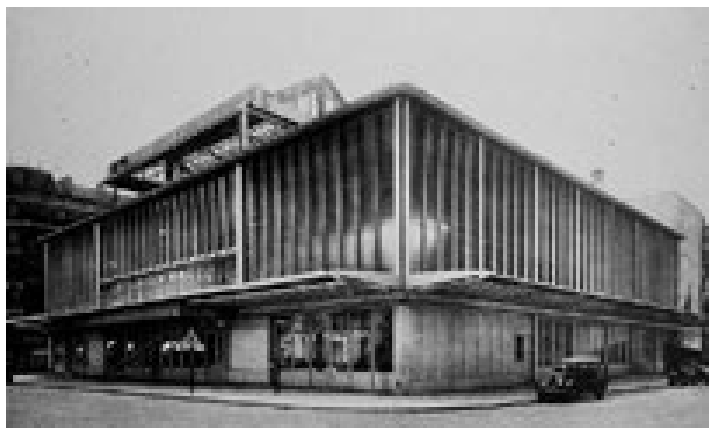

Figuras 8 y 9. Vista (v) exterior y corte longitudinal de la Maison du Peuple en Clichy (1939) de Eugène Beaudouin, Marcel Lods, Vladimir Bodiansky y Jean Prouvé

Fuente: "Le marché couvert de Clichy (Seine)" (Filippi, 1939, pp. 518 y 523). Odin sus o etiferet publiu inteati derriam 
dida por Auguste Perret (1874-1954) y sus discípulos. De hecho, a lo largo del siglo XX jamás cesaría la influencia de los tipos americanos, no solo en los edificios de habitación, sino también en los edificios de oficinas, los comerciales y las fábricas. Hoy por hoy, resulta absolutamente vano intentar interpretar, a cualquier precio, las obras construidas o aquellas simplemente proyectadas, dentro de un ámbito estrictamente nacional: se impone necesariamente una historia transnacional.

Una historia transdisciplinar también se hace necesaria, y sería seguramente no menos fecunda. La eficacia visual de las ilustraciones y de la puesta en página de Bauen in Frankreich, Eisen, Eisenbeton, hace que resulte más sorprendente la apatía de Giedion frente a otras dimensiones de la obra de arquitectos que él mismo valoraba, quienes en su gran mayoría mantuvieron una estrecha e intensa relación con la literatura. Hoy sabemos que los arquitectos modernos fueron constructores, del mismo modo en que eran ávidos lectores: Le Corbusier, por ejemplo, devoró en 1908 y hacia finales de los años cincuenta Also sprach Zarathoustra (Así hablaba Zaratustra) in Frankreich, Eisen, Eisenbeton (1928), realizada por Guy Ballangé y publicada en 2000 con un prólogo de Jean-Louis Cohen. Al igual que en la portada del texto de A. G. Meyer, también aparece la Galerie des machines (1889) Fuente: Giedion (2000)

(1) Figura 11. Portada de Eisenbauten: ihre Geschichte und Asthetik de Alfred Gotthold Meyer, publicado en 1907. En la imagen aparece la Galerie des machines (1889) del arquitecto Charles Dutert y el ingeniero Victor Contamin

Fuente: Meyer (1907).

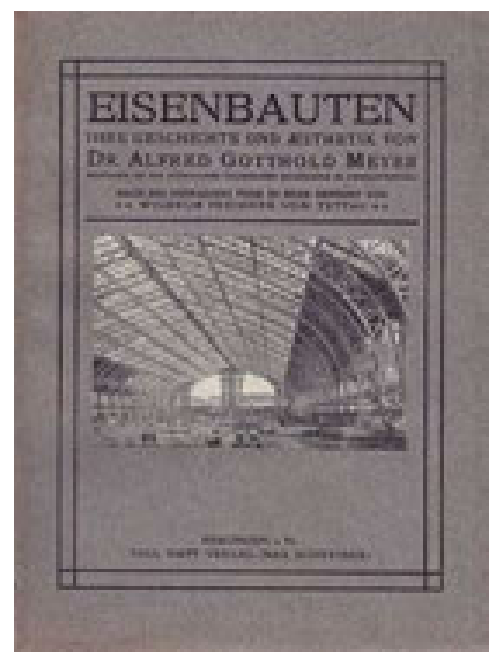

$\otimes$ Figura 12. Vista actual de la fachada suroccidental del edificio principal de la Unesco en París

Fuente: Andrés Ávila-Gómez (2018). CC BY-NC-ND.

\section{Los arquitectos y el libro}

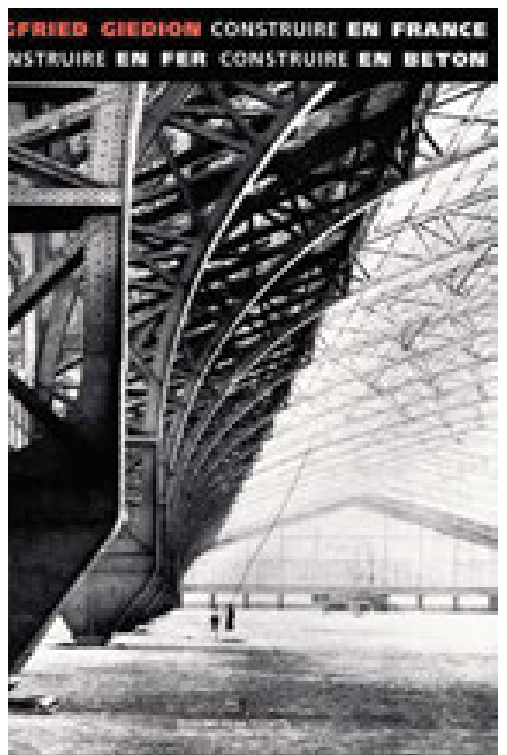

de Friedrich Nietzsche (1844-1900), que se convirtió por toda Europa en el libro de cabecera para muchos arquitectos de la misma generación de Le Corbusier ${ }^{22}$, quien fuese además un gran lector de Jean-Jacques Rousseau (1712-1778). Sin duda, el arquitecto franco-suizo extrajo de los poemas de Stéphane Mallarmé (1842-1989) algunos de los eslóganes que lo volvieron célebre, y supo también sacar provecho de la lectura de L'Homme et la Coquille de Paul Valéry ${ }^{23}$ (1871-1945); y ya en sus últimos años, un ya mundialmente famoso Le Corbusier aprovechaba el tiempo durante los largos vuelos hacia la India, para leer y anotar sin descanso el Pantagruel de François Rabelais (1494-1553), el Don Quijote de la Mancha de Miguel de Cervantes (1547-1616), o La Part maudite de Georges Bataille (1897-1962).

Por su parte, Auguste Perret, mentor de Le Corbusier, había encontrado en el texto Eupalinos ou l'architecte (Figura 13) de Paul Valéry -escrito en 1921 para acompañar una recopilación de trabajos de los decoradores Louis Suë (1875-1968) y André Mare (1885-1932)-, la inspiración para componer los aforismos, a menudo solemnes, que encontramos en la base de su discurso teórico. Otro caso Ilamativo: antes de rebelarse contra la École des Beaux-Arts desde su filial romana, la célebre Villa Medici, Tony Garnier (1869-1948), un típico arquitecto beauxartiano ganador del Grand Prix de Rome en 1899, extrajo a su vez de uno de los cuatro Évangiles (Evangelios) de Émile Zola (1840-1902), el programa de su "Cité industrielle" (Ciudad Industrial) (Figura 14), un proyecto ideal diseñado por Garnier en fases sucesivas entre 1901 y $1917^{24}$.

No contentos con ser sus lectores, los arquitectos son frecuentemente también verdaderos

22 Ver Nietzsche and "An Architecture of Our Minds" (Kostka y Wohlfarth, 1999).

23 Ver Der Architekt am Strand. Le Corbusier und das Geheimnis der Seeschnecke (Maak, 2010).

24 Ver Tony Garnier, I'œuvre complète (Guiheux y Cinqualbre, 1990).

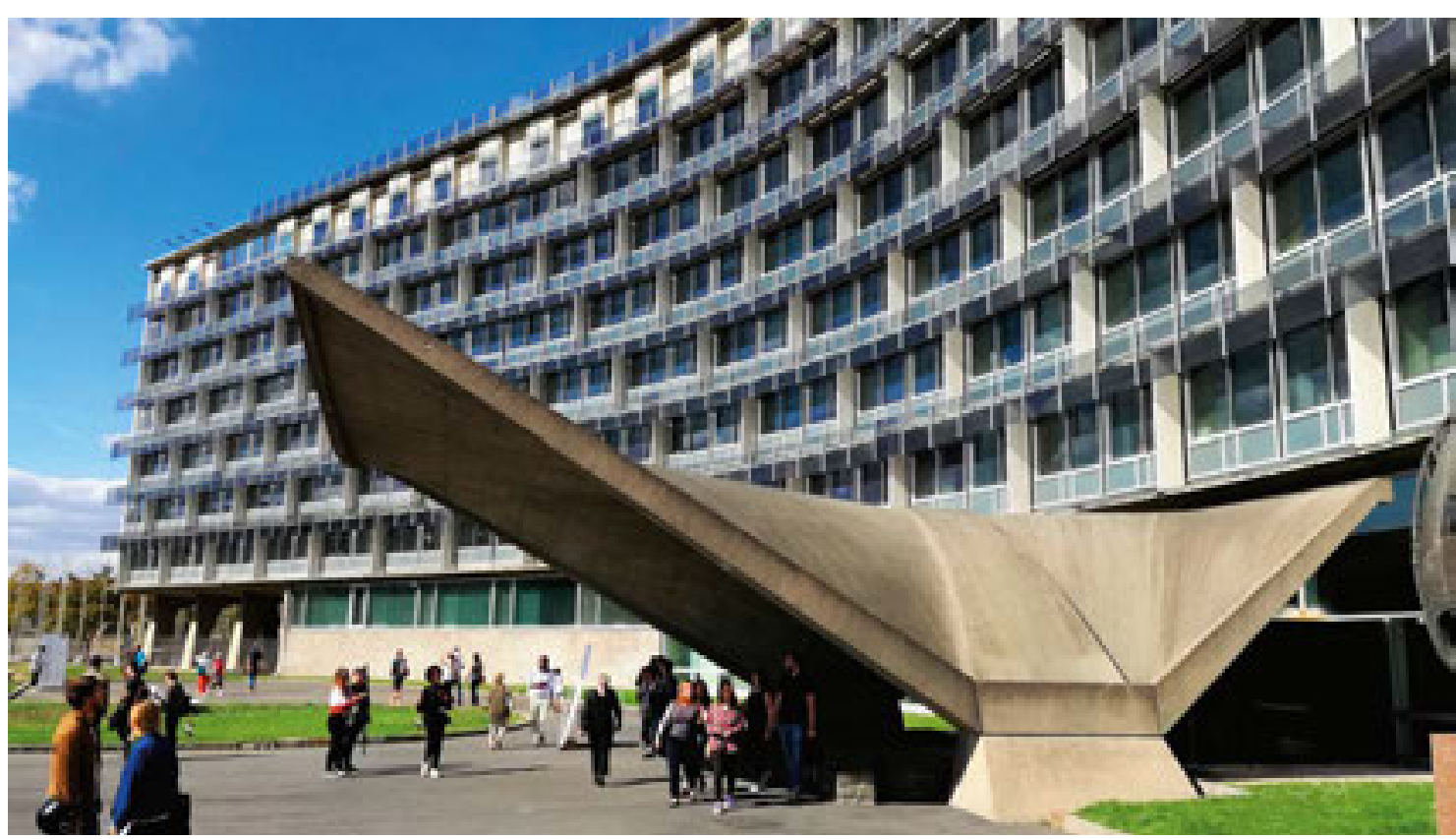


interlocutores de escritores y filósofos, tanto como aquellos lo son a veces de los artistas, al punto de rendirles no pocas veces homenajes. Este fue el caso de arquitectos como Henry van de Velde (1863-1957) quien diseñó varios proyectos que rendían homenaje a Nietzsche, e intervino entre 1902 y 1903 la Villa Silberblick en Weimar edificio que alberga desde 1897 los archivos de filósofo alemán. O también de arquitectos como Louis Bonnier (1856-1946) un adepto convencido del Art Nouveau, quien construyó entre 1904 y 1907 en París la casa del escritor André Gide (1869-1951) -Premio Nobel de Literatura en 1947-, más conocida como Villa Montmorency; o como Frantz Jourdain (1847-1935), el arquitecto de las reconocidas tiendas comerciales de La Samaritaine, quien transmitió a Émile Zola valiosa información sobre aquellos grandes almacenes, que sería magistralmente usada por el escritor en su obra Au bonheur des dames (traducido como: El paraíso de las damas); y que a la postre diseñaría más tarde la tumba de Zola ${ }^{25}$ (Figura 15).

Pero Jourdain, quien fue también crítico de arte y escritor, era más cercano entonces a los hermanos Jules y Edmond de Goncourt que al autor de la serie de novelas Les Rougon-Macquart, y en 1893 dedicó a Jules de Goncourt su novela L'Atelier Chantorel, extensa diatriba contra la École des Beaux-Arts, en la cual el autor estigmatiza la crasa ignorancia de sus antiguos condiscípulos, hostiles al arte, a la música y a la literatura contemporánea ${ }^{26}$.

En Francia, tales encuentros entre arquitectos y escritores iban desde la simple colaboración hasta la estrecha amistad, pero no son comparables con lo que ocurría en el marco de la Akademie der Künste prusiana, en donde se juntaban -al menos hasta 1933-, personalidades como Thomas Mann (1875-1955) y Mies van der Rohe (1886-1969). Continuando con ejemplos alemanes, uno de los cambios visibles en el debate público producido durante la segunda posguerra lo constituyó la Darmstädter Gespräch de 1951, en donde Martin Heidegger (1889-1976) pronunció su conferencia "Bauen, wohnen, denken" (Construir, habitar, pensar) que marcó el encuentro entre la fenomenología y la arquitectura, motivando el cuestionamiento público de los ideales de la Bauhaus ${ }^{27}$.

En Italia, durante aquel mismo periodo se presenció un diálogo apasionado entre arquitectos, escritores y cineastas del neorrealismo: encuentros institucionales y acciones grupales de esa naturaleza no se presentaron en Francia, en donde la tradición antiintelectual característica de la École des Beaux-Arts parecía perpetuarse. Para el historiador y crítico Bruno Zevi (1918-2000), ninguna solución de continuidad entre la arquitectura y la cultura parecía posible:

25 Aunque sepultado en el cementerio de Montmartre, las cenizas de Zola fueron trasladadas en 1908 al célebre Panteón de París.

26 Ver la dedicatoria de Jourdain en L'Atelier Chantorel (Charpentier y Fasquelle, 1893).

27 Ver "Bauen, wohnen, denken" (Heidegger, 1952).
Zevi fue quizás el primero en sugerir el sintagma de "cultura arquitectónica" en su impugnación a Espace, temps, architecture, catecismo escrito en 1941 por Sigfried Giedion para celebrar la hegemonía de Le Corbusier y de Walter Gropius. Zevi escribió: "L'architecture et la culture architecturale s'identifient. Si l'architecture n'est pas soutenue par un esprit critique fécond, vivant, stimulateur [stimolatore], elle s'effondre dans le maniérisme» ${ }^{28}$ (1949, p. 11).

De manera recíproca, muchos escritores prestaban especial atención a la arquitectura. Años antes, Zola, por ejemplo, además de estudiar concienzudamente las grandes tiendas comerciales parisinas, había cuestionado insistentemente en sus novelas el futuro de la construcción. En L'CEuvre (La obra) Zola tomó partido, prestándole a su personaje Claude Lantier -inspirado en Paul Cézanne- un verdadero programa así descrito:

Quelque chose d'immense et de fort, de simple et de grand, ce quelque chose qui s'indiquait déjà dans nos gares, dans nos halles, avec la solide élégance de leurs charpentes de fer, mais épuré encore, haussé jusqu'à la beauté, disant la grandeur de nos conquêtes ${ }^{29}$ (1886, pp. 176177).

\section{Los escritores frente a la arquitectura}

Por su condición de campo abierto y fértil a la imaginación prospectiva, la arquitectura ha sido considerada por los escritores siempre a partir de sus principios y según sus vínculos con las otras artes. En su primer texto titulado "Paradoxe sur l'architecte", publicado en 1891, Paul Valéry hacía eco del filósofo prusiano Friedrich ScheIling (1775-1854), quien había visto en la arquitectura una gefrorene Musik (música congelada),

28 "La arquitectura y la cultura arquitectónica se identifican entre sí. Si la arquitectura no se apoya en un espíritu crítico fecundo, vivo y estimulante [stimolatore], se diluirá en el manierismo".

29 "Algo inmenso y sólido, simple pero grande, algo que estaba ya presente en las estaciones de tren y en los mercados, con aquella firme elegancia de sus cubiertas de hierro, pero depurado y elevado hasta el punto de hacerlo algo bello, capaz de plasmar la grandeza de nuestras conquistas".
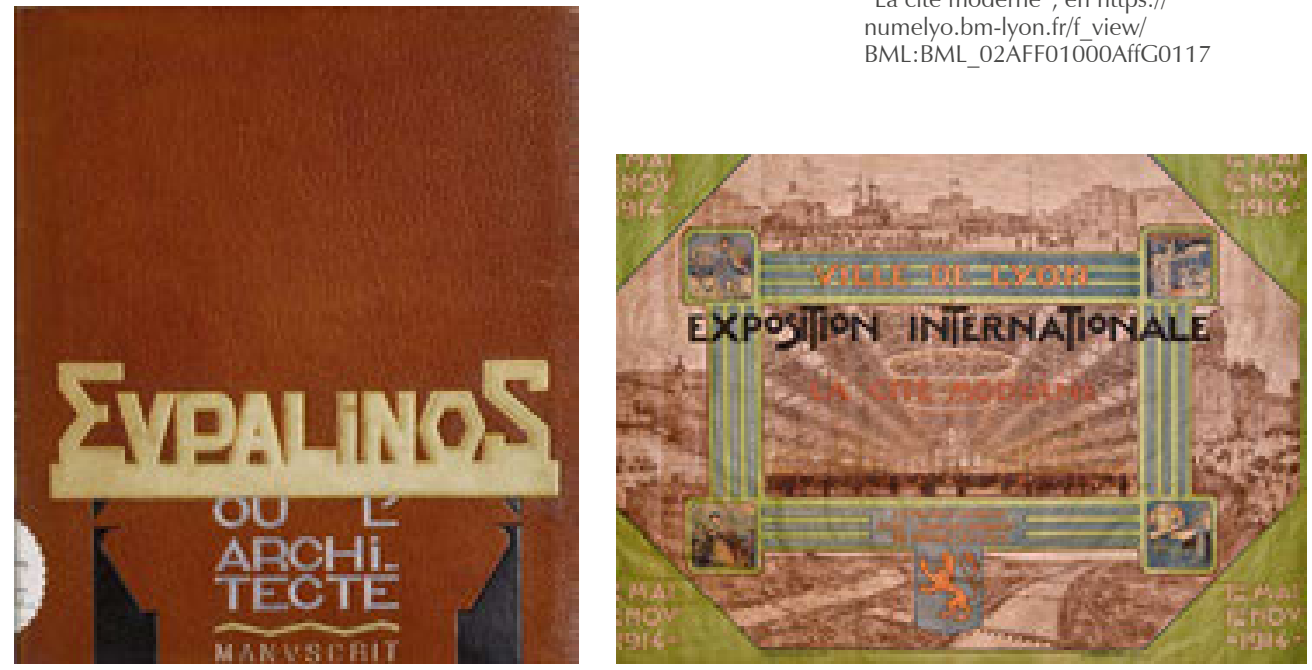

Encuadernación (realizada por original de Eupalinos ou I'architecte de Paul Valéry Fuente: Gallica - Bibliothèque Nationale de France*. Département des manuscrits. NAF 25537. Dominio público.

(1) (1) Figura 14. Afiche $(116 \times 155 \mathrm{~cm})$ de la Exposition internationale "La cité moderne" (1 mayo - 1 noviembre 1914). Tony Garnier Fuente: Numelyo Bibliothèque municipale de Lyon $^{* *}$ (AffG0117). Dominio público - Licence OuverteOpen Licence.

* Eupalinos ou l'A chitecte Mascit Paul Valéry, en https://gallica.bnf. fr/ark:/12148/btv1b53157079c f4.image. $r=$ eupalinos $\% 20$ ou\%20l'architecte\%20paul\%20 val\%C3\%A9ry

**Exposition internationale, "La cité moderne", en https:// BML:BML 02AFF01000AffG0117 
$\rightarrow$ Figura 15. Monumento funerario en honor de Émile Zola (1902), concebido por Frantz Jourdain. Cementerio de Montmartre en París

Fuente: Jean-Louis Cohen (2012). CC BY-NC-ND. $\rightarrow$ Figure 16. Portada de la segunda edición (1904) de la traducción al francés de The Bible of Amiens (1884) de John Ruskin: La Bible d'Amiens, traducción, notas y prefacio de Marcel Proust

Fuente: Gallica - Bibliothèque nationale de France*

département Littérature et art, 8-Z-5691. Dominio público.

*La Bible d'Amiens (2e édition), en https://gallica.bnf.fr/ark:/12148/ bpt6k97739274/f9
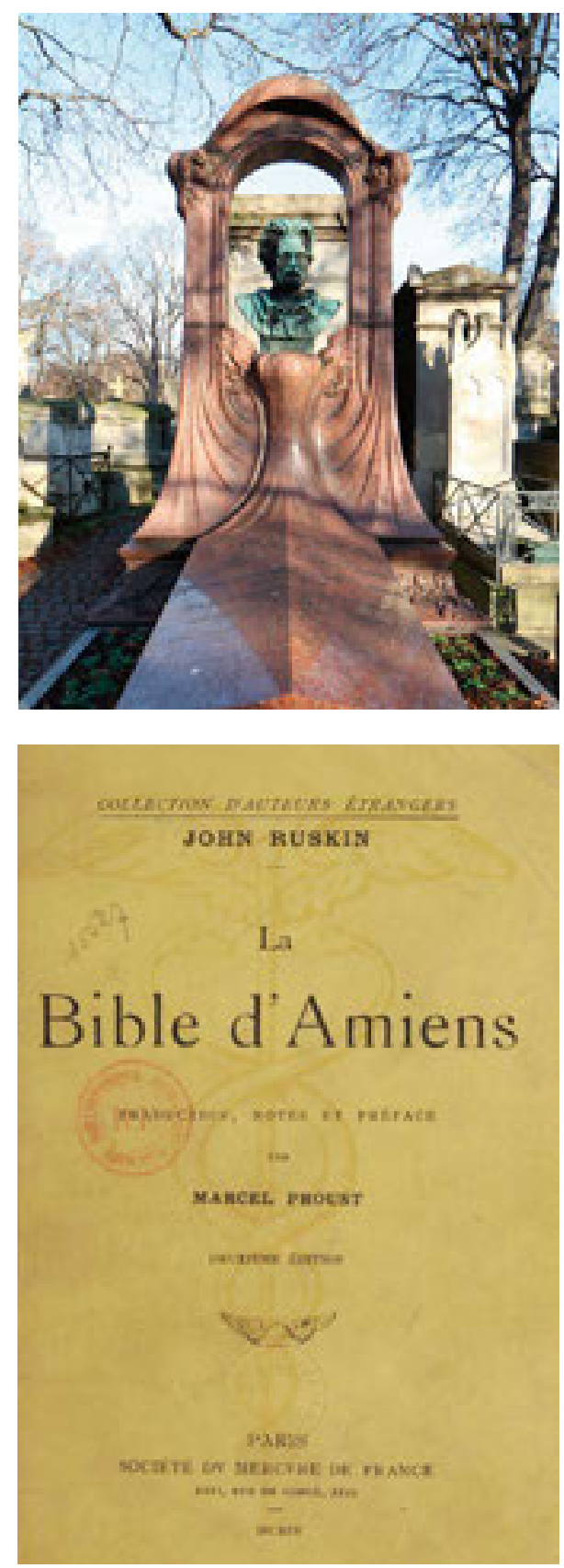

comparando al "arquitecto del futuro" con un músico:

Quand, libre des choses visibles et des types exprimés, il aura trouvé le symbole et la synthèse de l'univers intérieur qui confusément l'inquiétait, lors cette volonté de musique agrandie composera sa création originale comme une haute symphonie [...]. Ainsi, se manifestera l'indicible correspondance, l'intime intimité qu'il faut discerner, sous des voiles habituels et mensongers, entre deux incarnations de l'art, entre la façade royale de Reims et telle page de Tannhäuser, entre I'antique magnificence d'un grand temple héroïque et tel suprême andante brûlant de flammes glorieuses. ${ }^{30}$

30 "Cuando, libre de las cosas visibles y de los tipos impuestos, él [el arquitecto del futuro] encuentre el símbolo y la síntesis del universo interior que confusamente lo inquietan, en aquel momento la voluntad de aquella música engrandecida [la arquitectura] compondrá su creación más original como si se tratara de una sinfonía [...]. De esta manera se manifestará la inefable correspondencia, la íntima paz que es necesario discernir - bajo los habituales y falaces velos - entre dos encarnaciones del arte: entre la fachada real de Reims y alguna página de Tannhäuser, entre la vetusta magnificencia de algún gran templo heroico y un soberbio andante exhalante de llamas gloriosas". (Valéry, "Paradoxe sur l'architecte", L'Ermitage, 3, mars 1891, en CEuvres, 1957, p. 1494). Ver Monique Parent (1999).
Otra homología posible es aquella que se manifiesta entre la estructura del edificio y la estructura del libro. El novelista Marcel Proust (1871-1922), amigo del historiador del arte Émile Mâle (1862-1954), y quien conocía los análisis desarrollados por Viollet-le-Duc (1814-1879), a quien había leído en la época en que tradujo al francés The Bible of Amiens (La Biblia de Amiens) (Figura 16) de John Ruskin (1819-1900), confesó en 1919 que había tomado la catedral como principio organizador de su célebre obra ${ }^{31}$ A la recherche du temps perdu compuesta por siete tomos escritos entre 1906 y 1922.

Proust reconoció también, en una carta dirigida al pintor Jean de Gaigneron:

Quand vous me parlez de cathédrale, je ne peux pas ne pas être ému d'une intuition qui vous permet de deviner ce que je n'ai jamais dit à personne et que j'écris ici pour la première fois: c'est que j'avais voulu donner à chaque partie de mon livre le titre: Porche I, Vitraux de l'abside, etc. pour répondre à l'avance à la critique stupide qu'on me fait du manque de construction dans des livres où je vous montrerai que le seul mérite est dans la solidité des moindres parties ${ }^{32}$.

Se puede apreciar en esta homología presente en la obra de Proust una anticipación a aqueIla establecida por Erwin Panofsky (1892-1968) entre la tesis escolástica y la catedral gótica. Al buscar otro caso histórico más distante, podemos citar a Santo Tomás, cuya Summa Theologiae se funda en una analogía con la arquitectura. Este tratado, escrito entre 1266 y 1274, resultó ser una fuente esencial para otro lector concienzudo, como lo era Mies van der Rohe ${ }^{33}$.

En un artículo incluido en 1929 en el Dictionnaire critique, Georges Bataille condenaba la "chiourme architecturale" que inspiran los grandes monumentos, subrayando de paso la presencia en aquel orden de un aparato tiránico que actuaba incluso más allá que en la propia arquitectura, "en la fisonomía del vestido, de la música o de la pintura". La arquitectura aparece, así como una fuerza capaz de silenciar las "multitudes" a través de una "lógica de la majestad y de la autoridad". ${ }^{34}$ En el momento mismo en que Bataille redactaba su artículo, se desarrollaba un programa

31 Ver "Émile Mâle et le secret perdu de la Recherche" (Fraisse, 2003, pp. 9-34).

32 "Cuando usted me habla de una catedral, no puedo evitar el hecho de sentirme conmovido por esa intuición que le permite a usted percibir lo que yo en cambio nunca he podido decir a nadie, y que escribo aquí por primera vez. Y esto es, que siempre quise dar a cada una de las partes de mi libro [A la recherche du temps perdu] un título así: Pórtico I, Vitrales del ábside, etc., para responder de esta manera y por anticipado a la crítica estúpida que se me hace argumentando una supuesta ausencia de estructura en mis libros, en los cuales puedo, sin embargo, demostrar que el gran mérito que poseen radica en la solidez existente en cada una de sus más ínfimas partes". Carta de Marcel Proust a Jean de Gaigneron (agosto de 1919), citada por Jean Rousset en Forme et signification. Essai sur les structures littéraires de Corneille à Claudel (1966, p. 137).

33 Sobre las lecturas de Mies van der Rohe, ver Mies van der Rohe. Réflexions sur l'art de bâtir (Neumeyer, 1996).

34 Ver "Architecture" de Georges Bataille (1929, p. 117). 
sin precedentes de construcción de vivienda gracias a la ley de financiamiento público de vivienda -más conocida como "loi Loucheur de 1928", por el apellido del entonces ministro de Trabajo, Louis Loucheur-, que dio inicio a una especie de apropiación popular de la arquitectura, cuyas manifestaciones sobre el terreno tomaron un sentido totalmente diferente a lo conocido hasta entonces. Al equiparar la arquitectura con un ordenamiento monumental y unas estructuras de dominación, Bataille dejaba de lado la dimensión más cotidiana de la arquitectura. Quizás Bataille retomó, a su manera, la convicción expresada en 1910 por Adolf Loos:

\section{II n'y a qu'une faible partie du travail de l'ar- chitecte qui soit du domaine des Beaux-Arts: le tombeau et le monument commémoratif. Tout le reste, tout ce qui est utile, tout ce qui répond à un besoin, doit être retranché de l'art. (1979, p. 226$)^{35}$}

La brillante acusación lanzada por Bataille se basaba en una reducción implícita de la arquitectura a aquellos grandes edificios en los cuales se condensa y se pone en escena el poder. Mi generación compartió esta visión antiautoritaria que años más tarde se transformó en una especie de "retorno de lo reprimido"36 (return of the repressed), en un formalismo descontrolado. Pero solo durante el siglo $\mathrm{XX}$, la arquitectura en su naturaleza a la vez práctica, artística y técnica dejó de estar destinada exclusivamente a la aristocracia y a la burguesía, y pasó a dar estructura y forma a programas destinados a las clases populares.

En este punto, me parece pertinente pasar del libro de piedra al libro de papel: aquellos dos términos que supo oponer Victor Hugo (18021885). Lejos de tratarse de unos fanáticos del ordenamiento del mundo, los arquitectos se han preocupado tanto por la concepción de edificios como también por la concepción de libros de naturaleza tan diversa como aquellos a través de los cuales ellos mismos han transmitido los principios de su arte - pasando por Vitruvio, Vignole, o su descendiente moderno, el funcionalista Ernst Neufert $^{37}$ (1900-1986), tan cercano a Walter Gropius, y más tarde a Albert Speer (1905-1981)-, o como aquellos a través de los cuales han pretendido la divulgación de su obra construida -como los Quattro Libri de Andrea Palladio o la OEuvre complète de Le Corbusier-. El papel no sustituyó a la piedra, como lo había anunciado Víctor Hugo en su novela Notre-Dame de Paris (Figuras17 y 18): y esto se debe precisamente al hecho de que la arquitectura haya podido resistirse y perpetuarse a través de los libros, los cuales constituyen hasta nuestros días un vector fundamental de la arquitectura.

35 "Solo una mínima parte del trabajo del arquitecto pertenece al terreno de las Bellas artes: la tumba y el monumento conmemorativos. Todo lo demás, todo aquello que es útil, todo aquello que responde a una necesidad, debe estar aislado del arte".

36 Retour du refoulé: concepto del psicoanálisis, fundamental en la obra de Freud.

37 Ver Ernst Neufert: normierte Baukultur im 20. Jahrhundert (Prigge, 1999).
También encontramos libros cuya escritura representó una forma de evasión o de distanciamiento con la arquitectura para algunos autores formados en esta disciplina como Michel BataiIle (1926-2008) en Francia; Siegfried Kracauer (1889-1966) en Alemania -quien se convirtió en cronista e historiador del cine-; o el suizo Max Frisch (1911-1991) -quien hizo una importante carrera como autor dramático-. Para quienes permanecen fieles a su disciplina de origen, la escritura hace parte del "sueño leonardiano" del arquitecto: concepto acuñado por Umberto Eco en su prólogo a la traducción francesa de II territorio dell'architettura de Gregotti, con el cual "refleja el ideal renacentista del intelectual integral que busca armonizar a través de su proyecto todos los problemas y todas las respuestas de la cultura de su tiempo" ${ }^{\prime 38}$.

La poligrafía alcanza formas extremas cuando observamos la obra de Viollet-le-Duc, Frank Lloyd Wright o Le Corbusier, cuya obra construida fue acompañada por una abundante producción escrita, ampliamente heterogénea en sus géneros y objetivos, yendo desde el panfleto a la simple confidencia, o del manifiesto al álbum ilustrado. Entre los arquitectos, dicha pulsión hacia la escritura ha estado fundamentalmente ligada a la búsqueda de estrategias de persuasión, sumándose a aquel otro impulso que lleva a tantos arquitectos a redactar textos netamente prescriptivos o a veces simples reportes de su producción, en la medida en que con ello logren formular los cuadros teóricos o biográficos que vuelvan comprensibles sus proyectos $^{39}$.

Muy pocos arquitectos reconocidos profesionalmente se han embarcado en la escritura de obras de corte literario, como Fernand Pouillon o, más recientemente, Paul Andreu ${ }^{40}$ (1938-2018); pero el género más usual ha sido sin duda alguna el de las memorias, en vista también de la relativa facilidad con la cual este género suele ser publicado -muchas veces con recursos financieros de los autores-. En tal sentido, vale decir que, escapando excepcionalmente a la indulgencia, las reminiscencias de arquitectos como Georges Candilis (1913-1995), Pierre Dufau (1908-1985), Marcel Lods o Pierre Vago (Figuras 19 y 20) (1910-2002) pasan por confidencias narcisistas que deben ser leídas con prudencia ${ }^{41}$.

Junto a los enunciados doctrinales y a otros instrumentos de persuasión, los libros toman también la forma de reportajes a fin de abrirle los ojos al público ante las realidades desconocidas o desapercibidas. Le Corbusier, por ejemplo,

38 Ver el prefacio de Umberto Eco publicado en la traducción francesa (Le Territoire de l'architecture, Gregotti, 1982, p. 8).

39 Ver actas del coloquio L'Architecte à la plume, organizado en mayo de 2010 por la Université Paris X junto con la École nationale supérieure d'architecture de Paris La Villette.

40 Ver Mémoires d'un architecte (Pouillon, 1968) y Enfin: roman (Andreu, 2014).

41 Ver Bâtir la vie (Candilis, 1977); Un architecte qui voulait être architecte (Dufau, 1989); Le Métier d'architecte: entretiens avec Hervé Le Boterf (Lods, 1976); Une vie intense (Vago, 2000). 
invitaba a sus lectores a abrir los ojos que "no veían" los barcos, los autos y los aviones -según una figura por lo demás demasiado mallarmeana42-, cincuenta años antes de que Paul Virilio (1932-2018) nos invitara a observar los bunkers del Muro Atlántico (Atlantikwall), y que Rem Koolhaas nos revelara los misterios del Delta del Río de las Perlas (Pearl River Delta) en la China meridional43.

Los libros escritos y siempre ilustrados de forma llamativa por arquitectos constituyen por lo general, en sí mismos, extraordinarios proyectos gráficos y hermosos objetos estéticos. Siempre atento a lo que él denominaba lo "físico" del libro, Valéry tomó prestado a Le Corbusier uno de sus eslóganes para definir el libro contemporáneo como una perfecta "machine à lire" (máquina de lectura); y en efecto, el poeta definía así las dos virtudes de un libro:

\begin{abstract}
À côté et à part de la lecture même, existe et subsiste l'aspect d'ensemble de toute chose écrite. Une page est une image. Elle donne une impression totale, présente un bloc ou un système de blocs et de strates, de noirs et blancs, une tache de figure et d'intensité plus ou moins heureuses. Cette deuxième manière de voir, non plus successive et linéaire et progressive comme la lecture, mais immédiate et simultanée, permet de rapprocher la typographie de I'architecture. (Valéry, 1960, pp. 1246-1247) ${ }^{44}$
\end{abstract}

42 Ver la introduccion de Jean-Louis Cohen en Toward an Architecture [1923] (Getty Research Institute, 2007, pp. 5-82).

43 Ver Bunker archéologie (Virilio, 1975) y Great Leap Forward (Chung, Inaba, Koolhaas, Leong, 2001).

44 "Simultáneamente, y al margen de la lectura en sí misma existe y subsiste el aspecto de conjunto de todo texto escrito: una página es una imagen, esta da una impresión total, presentando un bloque o un sistema de bloques y de estratos, negros y blancos. Esta segunda manière de voir, ya no sucesiva, lineal y progresiva como lo es la lectura, sino inmediata y simultánea, permite relacionar la tipografía con la arquitectura".

\section{Del edificio a la ciudad: sobre la arquitectura y la forma urbana}

La modernidad agudizó la tensión entre el edificio y la ciudad, al punto que una de las razones para la hostilidad que debió enfrentar en muchos países la nueva arquitectura tuvo que ver con su capacidad para generar entornos urbanos habitables; y esto debido a razones que no le son siempre atribuibles, en la medida en que la arquitectura se vio afectada por crisis y por fenómenos de desigualdad, así como por aquello que denomino la "distorsión estatal o mercantil de los ideales modernos". A este respecto, no pueden pasarse por alto ciertas consideraciones sociales que explican por qué dos edificios casi idénticos formalmente pueden tener destinos opuestos, tal y como ha sucedido con las unités d'habitation de Le Corbusier (Figura 21): una inversión refinada para universitarios y psicoanalistas, en el caso de Marsella; o una carcasa en estado de abandono tras la deserción masiva de los desempleados del sector de la siderurgia, en el caso de Briey-en-Forêt (región de la Lorraine). Estas dos situaciones urbanas tan disímiles llevaron a que un prototipo optimista pasara a ser asociado con un modelo ruinoso, si bien en el caso de Brieyen-Forêt sus defensores lograron inventarle una nueva vocación.

El objeto arquitectónico es susceptible de ser proyectado de acuerdo con sus reglas autónomas de concepción y de producción, las cuales pueden ser objetivadas y analizadas según varios métodos en los cuales las conexiones con el campo literario son evidentes. Puede citarse, por ejemplo, el caso del análisis genético promulgado por Pierre-Marc de Biasi (1950-), tan eficaz para rastrear las etapas del proceso de concepción ${ }^{45}$;

45 "Architecture", Genesis, 14, 2000
Figura 17. Ilustración del portal de Notre-Dame de Paris en la tercera edición de la novela de Victor Hugo, publicado por el editor C. Gosselin en 1831

Fuente: Gallica - Bibliothèque nationale de France*, Département Littérature et Art, 8-Y2 63002 (2). Dominio público.

$\rightarrow$ Figura 18. Notre-Dame de Paris, en una versión de la novela de Victor Hugo, ilustrada por Gustave Brion y con gravados de Edmond Ch. J. Yon y Georges L. A. Perrichon, publicada por los editores J. Hetzel y A. Lacroix en 1865 Fuente: Gallica - Bibliothèques de Marseille** 2016-178755. Dominio público. *Carátula de Notre-Dame de Paris, de Victor Hugo, en https://gallica.bnf.fr/ark:/12148/ bpt6k6497803t?rk=42918;4

**Notre-Dame de Paris, ilustrada por Gustave Brion, en https://gallica.bnf.fr/ark:/12148/bpt6k9742207t/f8.item

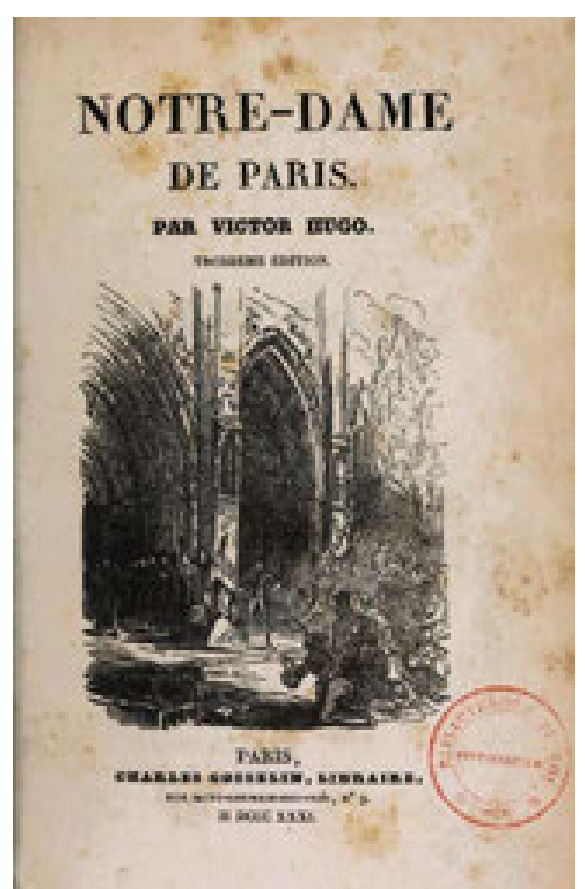

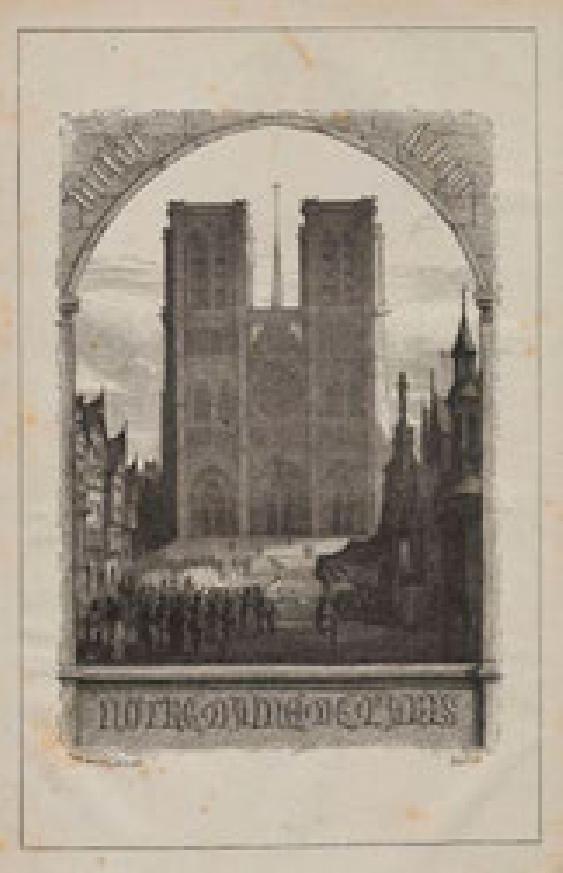


o incluso, el trabajo de Bruno Reichlin (1941-) quien utiliza las figuras de la retórica para dar cuenta de los dispositivos imaginados por Luigi

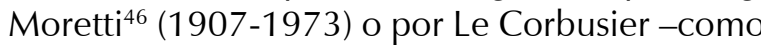
en la hermosa interpretación de Reichlin acerca de las aperturas de la villa Church $^{47}$ (construida en Ville d'Avray, entre Versalles y París)-.

La relación entre el objeto arquitectónico, y el espacio urbano y el paisaje estuvo en el foco de atención de dos generaciones durante la segunda mitad del siglo pasado, haciéndose presente en tres libros fundamentales publicados con pocos meses de diferencia en 1966 - casi como si se hubiese planeado inaugurar el último tercio del siglo sobre unas nuevas bases -: L'architettura della città de Aldo Rossi (1931-1997), Il territorio dell'architettura de Vittorio Gregotti (1927-) y Complexity and Contradiction in Architecture de Robert Venturi (1925-2018). Rossi, apoyándose en los trabajos de los geógrafos franceses y en la noción de memoria colectiva desarrollada por el sociólogo francés Maurice Halbwachs (18771945), consideró la ciudad como un artefacto, y en cierta forma como una obra colectiva de arquitectura ${ }^{48}$. Gregotti, al referirse a la noción de territorio de manera metafórica -y en su esfuerzo por ampliar el contorno de la disciplina arquitectónica-, proyectaba la intervención del territorio a la escala de las grandes formaciones geográficas (Gregotti, 1966), Ilevándolo más tarde a la práctica en sus proyectos para las universidades de Florencia, Calabria y Palermo. Venturi, cuyo discurso se centraba en la obra aislada, entendió a partir del análisis de las iglesias romanas -con base en las cuales las cuales moldeó la noción de "inflexión"-, las relaciones presentes entre edificios y trazados urbanos (Venturi, 1976) ${ }^{49}$. Los libros de estos tres autores fueron publicados casi quince años antes de la afirmación de la actitud posmoderna marcada en la Bienal de Venecia de 1980 con la "Strada Novissima" (Figura 22), de Paolo Portoghesi (1931-).

Así, mientras en 1966 Gregotti intentó perpetuar la actitud de los modernos sugiriendo una arquitectura expandida a la escala de los grandes trazados paisajísticos, tanto Rossi como Venturi criticaron la idea de una arquitectura autónoma y centrada en sus propias reglas de constitución e ignorando la complejidad urbana.

Resulta difícil adjudicar al culto de la continuidad entre ciudad y arquitectura ilustrado por el episodio de los "proliférants", aquellos edificios piramidales tan de moda en Francia al iniciar los años setenta, tratándose de aquel culto cuya arquitectura conocida como "urbana" tuvo su mejor expresión entre los años sesen-

46 Ver Dalla "soluzione elegante" all' "edificio aperto". Scritti attorno ad alcune opere di Le Corbusier (Reichlin, 2013a).

47 Ver "Una sfida al sistema architettonico della tradizione. II padiglione Church a Ville d'Avray" (Reichlin, 2013b, pp. 207-233).

48 Ver: L'Architecture de la ville (Rossi, 2001).

49 Ver De l'ambiguïté en architecture (Venturi, 1976). ta y ochenta en Italia. Este discurso se prolongó hasta los análisis de Rafael Moneo o del propio Anthony Vidler (1941-), quien veía en la ciudad una "tercera tipología" en continuidad con el historicismo y la estética de la máquina ${ }^{50}$. Nuestra reflexión interroga -sin oponer al extremo los dos términos abordados- las formas múltiples, literales o estructurales propias de la relación entre el objeto construido y el entorno urbano, puesto que estos corresponden, no tanto a dos escalas diferentes, sino a dos sistemas técnicos, sociales y artísticos. Aunque la arquitectura se ve determinada por aspectos como las alturas, los alineamientos o las estéticas reglamentadas, esta se encuentra inscrita en el espacio urbano, y está constituida no solo por la conjugación de un sustrato geográfico, de flujos, de redes y de paisajes artificiales, sino también por la continuidad de los edificios.

Las ciudades han afectado los espacios rurales, cada vez más despoblados como resultado de migraciones sin precedentes, y es, sin embargo, en las ciudades en donde la modernidad y la modernización han encontrado su marco y su horizonte. Durante el primer tercio del siglo XX, la emergencia de la metrópolis -principalmente en Alemania y Estados Unidos- transformó las mentalidades, tal y como lo describe en sus análisis Georg Simmel, y condicionó así la arquitectura, tal y como lo indican en sus reflexiones sobre la forma y la estética de la Großstadt ${ }^{51}$, Karl Scheffler (1869-1951) o August Endell (1871-1925). Al mismo tiempo, los grandes edificios, desde las estaciones de tren hasta los grandes almacenes comerciales, condensaron los rasgos de la gran ciudad capitalista, tal y como lo revela de forma crítica Walter Benjamin en su obra.

El problema no se reduce a la inserción material en un organismo tan complejo como es la

50 Ver los artículos publicados en Oppositions: "On typology" (Moneo, 1978, pp. 23-45) y "The third typology" (Vidler, 1976, pp. 1-4)

51 Ver la antología, aún actual, titulada Metropolis: Saggi sulla grande città di Sombart, Endell, Scheffler e Simmel (Cacciari, 1973).
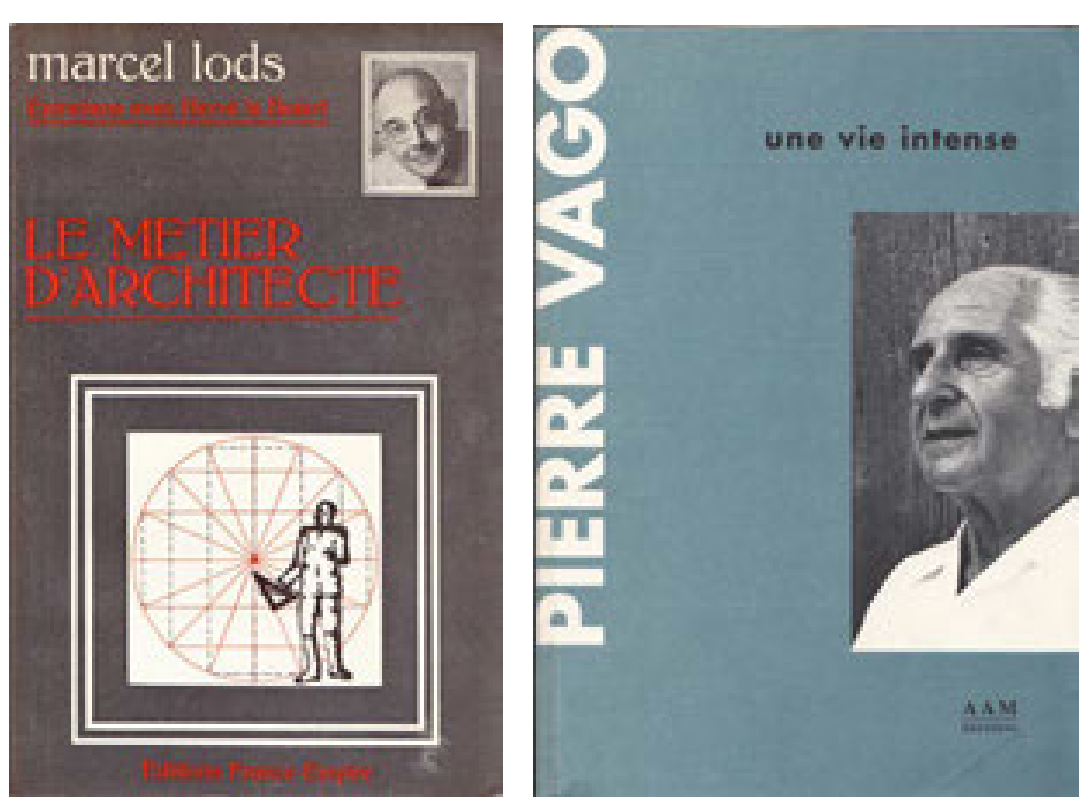

$\nabla$ (V) Figuras 19 y 20 Portadas de Le métier d'architecte y de Une vie intense

Fuentes: Marcel Lods (1976) y Pierre Vago (2000). 
ciudad -determinada por consideraciones políticas y económicas-, de un simple edificio, de un monumento o de una casa, al engranaje de algún proyecto promovido por agentes privados; o a la ejecución de algún programa público. Parámetros objetivos como pueden serlo la densidad, la altura, la axialidad o la topografía son objeto de interpretaciones subjetivas en las cuales intervienen mitos y representaciones. La elaboración de una arquitectura "parisina", "berlinesa" o "carioca" pasa por un ajustement con numerosos estereotipos, o, al contrario, por un esfuerzo inductivo para superarlos. Un esfuerzo de tal magnitud escapa a un razonamiento objetivo -o que se considere así- que es, en este caso, el de una arquitectura al servicio exclusivo del cliente, puesto que la imaginación se alimenta, como lo señala Hubert Damisch en Skyline. La ville Narcisse, ya sea de la fantasía o del deseo (1996, pp. 12-15).

A riesgo de caer en un excesivo esquematismo evocaremos las actitudes que se han sucedido o se han opuesto, en lo que respecta a la relación entre el edificio y la ciudad desde finales del siglo XIX. Las composiciones elaboradas por los antiguos alumnos de la École des Beaux-Arts no respondían únicamente a los programas monumentales de la Tercera República Francesa, ya fuera en París, en la provincia o en los territorios del imperio francés: dichas composiciones fueron exportadas al continente americano -desde Chicago hasta Buenos Aires-, a los Balcanes y al Oriente Medio, para dar forma a núcleos urbanos inspirados por el modelo haussmaniano. Paradójicamente, mientras que los proyectos diseñados

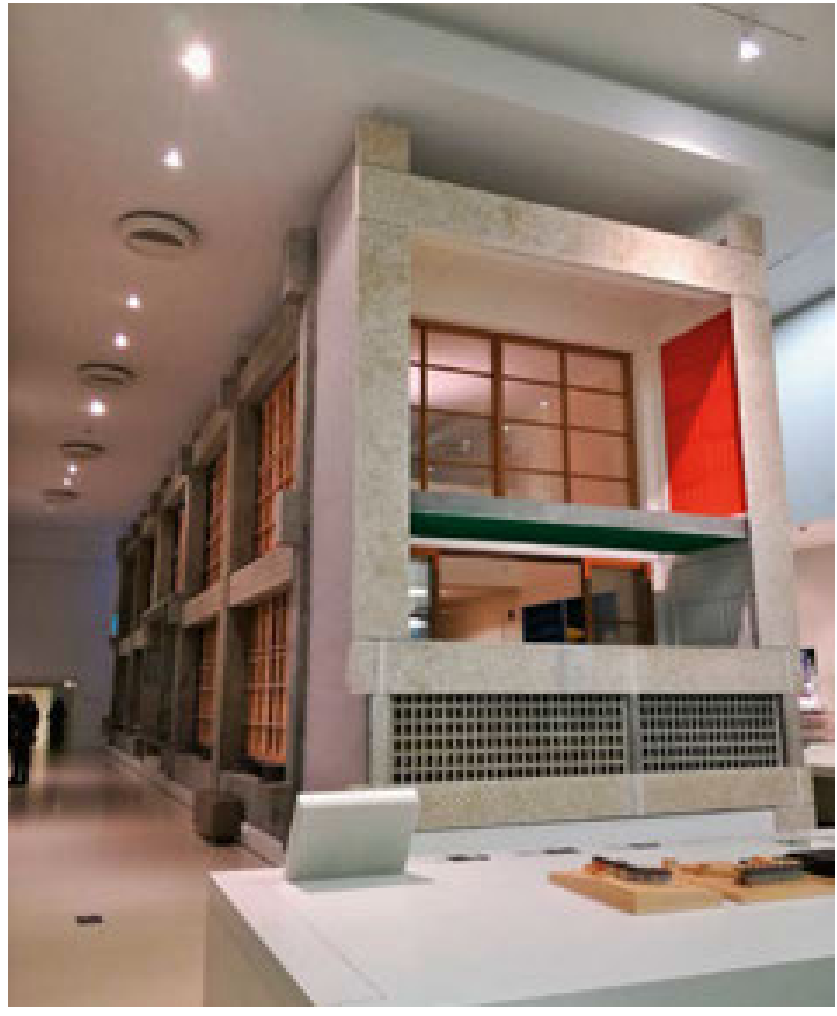

(A) Figura 21. Modelo de un apartamento tipo duplex de la Unité d'habitation de Marsella (construida entre 1946 y 1952), instalado de manera permanente en el espacio de la Galerie d'architecture moderne et contemporaine, de la Cité de l'architecture et du patrimoine. En este caso, la estructura usada para esta "retranscripción" es metálica y recubierta en concreto

Fuente: Andrés Ávila-Gómez (2018). CC BY-NC-ND. en la École des Beaux-Arts eran concebidos pensando en terrenos abstractos, siguiendo así una desdeñosa costumbre de indiferencia hacia el emplazamiento, sus combinaciones sobre plazas y a lo largo de calles constituyeron conjuntos urbanos coherentes, aunque a menudo excesivamente grandilocuentes.

Al orden sublime de las grandes plazas o de las vertiginosas perspectivas de los boulevards ordenados gracias a las horizontales trazadas por balcones, vendría a imponerse -en plena época de programas de reforma social-, un orden pintoresco fundado sobre un deseo de variedad en la cual fuera posible la individualidad del edificio. El reglamento de urbanismo de París, elaborado en 1902 por Louis Bonnier, representó este nuevo principio, manteniéndose en vigor durante los dos primeros tercios del siglo $X X^{52}$. La misma preocupación por el contraste y por la animación se hizo común en los proyectos de ciudades jardín (Garden cities), cuyas fuentes se encuentran en los trazados de los pueblos ingleses, franceses o alemanes. En 1909, en el manual titulado Town Planning in Practice, Raymond Unwin se apoyó en los croquis de los burgos normandos (Figura 23) para diseñar las plazas y las calles de sus ciudades-jardín británicas ${ }^{53}$ : las casas diseñadas en estos proyectos solo funcionan dentro de su sistema de yuxtaposición, pero de ningún modo lo harán si se aíslan unas de otras arbitrariamente.

Formados inicialmente según alguno de estos dos métodos -la composición axial o la composición pintoresca, o a veces las dos al tiempo-, los arquitectos y urbanistas modernos se opusieron con firmeza a toda continuidad posible con la ciudad del pasado; y esto debido fundamentalmente a la aversión hacia la ciudad antigua y por su deseo de afirmarse en contra de aquella. Así, por ejemplo, Frank Lloyd Wright había participado en la construcción de la Chicago moderna, mientras que Le Corbusier había sido inicialmen-

52 Ver Les Règlements de voirie (Bonnier, 1903). 53 Ver L'Étude pratique des plans de villes (Unwin, 1922).

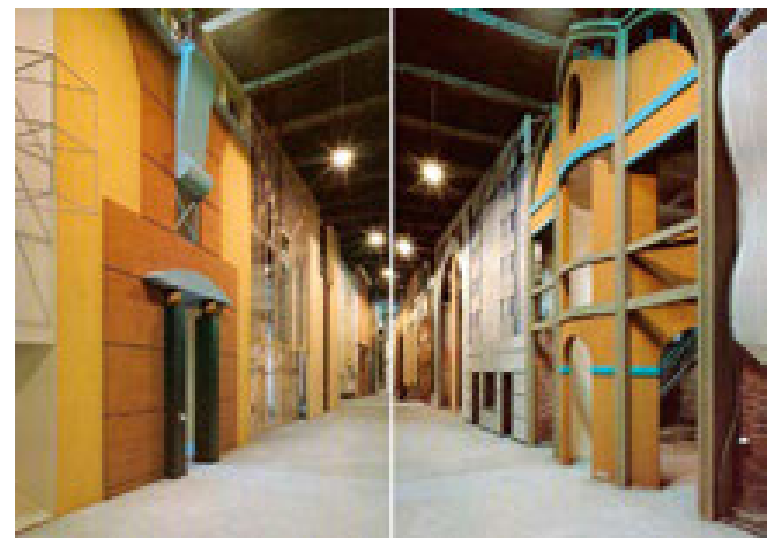

(A) Figura 22. Vista de la Strada Novissima en la Bienal de Arquitectura de Venecia de 1980 Fuente: foto publicada en Domus*, núm. 605.

La Strada Novissima: The 1980 Venice Biennale, en https://www.domusweb. it/en/from-the-archive/2012/08/25/-em-la-strada-novissima-em--the1980-venice-biennale.html 
te un ferviente defensor de la ciudad-jardín y de las ciudades medievales: $y$, sin embargo, el gran legado teórico y construido de Wright se caracteriza por su oposición a lo que representaba Chicago, así como el legado de Le Corbusier lo es por su oposición a lo que representaba París.

Si lo beauxartiano tendía a ignorar la ciudad existente y buscaba sustituirla por nuevos trazados axiales o pintorescos, los modernos fueron aún más radicales condenando su densidad e insalubridad, y proponiendo su destrucción: a la lógica de la intervención puntual o a aquella de la extensión por fragmentos, los modernos opusieron la alternativa de la capa de torres o de barras creada de acuerdo con el modelo de la industria fordista al servicio de los managers de la era de la organización. Apoyándose en la prefabricación y en una intervención pública coherente, este nuevo razonamiento permitió la producción en masa de viviendas de interés social, para responder en parte a las expectativas de la población -aunque resulta imposible saber si otras alternativas más convencionales no podrían haber tenido efectos similares o mejores a aquellos obtenidos-. Según Bernard Huet (1932-2001), La Charte d'Athènes, publicada en 1943 por Le Corbusier, sugirió entonces una "antinoción de la ciudad"54.

Al mismo tiempo, los arquitectos más radicales se regocijaban por una destrucción de las ciudades europeas que permitiría reemplazarlas por nuevas entidades racionales y cristalinas, de las cuales el célebre grand ensemble -conocido como "Cité des 4000 logements"-, construido en La Courneuve (en la periferia nororiental de París), pretendía ser un ejemplo. En Deux ou trois choses que je sais d'elle (Dos o tres cosas que sé de ella), película rodada en 1967 (Figura 24), Jean-Luc Godard (1930-) buscó ilustrar la noción: "d'ensemble envisagé comme en mathématiques, c'est-à-dire comme des structures totales où l'uni-té humaine de base est régie par des lois qui la dépassent, précisément parce que ce sont des "lois d'ensemble" 55 .

Las soluciones propuestas durante el siglo XIX, como la ciudad hausmanniana y su sistema de manzanas cerradas, pueden ser comparadas retrospectivamente con las barras producidas durante el siglo Xx: así lo ha hecho Christian de Portzamparc (1944-), estableciendo una "edad 1 " de la ciudad moderna caracterizada por la continuidad de su tejido y de sus calles-corredor, a la cual se opone una "edad 2" caracterizada por la dispersión del espacio con edificios discretos separados por superficies amorfas. A estas se

54 Ver el artículo de Huet publicado en Lotus: "La città come spazio abitabile, alternative alla Carta di Atene" (1984, pp. 6-17).

55 “... de conjunto considerado como en las matemáticas, es decir, como estructuras totales al interior de las cuales la unidad humana básica se encuentra regida por leyes que la rebasan totalmente, debido precisamente a su carácter de leyes de conjunto". Ver el guión de Jean-Luc Godard para Deux ou trois choses que je sais d'elle (1967, p. 169). suma la denominada "edad 3", de la cual el propio Portzamparc se erigió como estandarte con su concepto de "îlot ouvert" (manzana abierta) (Figuras 25 y 26); aunque poco se ha defendido la importancia de lo que me atrevo a denominar la "edad 1,5" que agrupa todas aquellas tentativas con las cuales se buscó transformar la ciudad de los primeros años de la era industrial y que no se reducen a la simple yuxtaposición de torres y de barras: podemos citar en esta "edad $1,5^{\prime \prime}$ las grandes manzanas propias de los planes alemanes desarrollados antes de 1914 ; el plano de Hendrik Petrus Berlage (1856-1934) para Amsterdam-sud en 1917; los conjuntos urbanos de la Roma de los años veinte; las barras urbanas concebidas por Giuseppe Terragni (1904-1943) en los años treinta; y, por supuesto, las ciudades-jardín de Radburn y de las Greenbelt Cities norteamericanas.

Al definir esta problemática es evidente que el término "edad" se vuelve un tanto impreciso por cuanto se constata una superposición temporal en relación con las tres "edades" definidas por Portzamparc, las cuales no son de ninguna manera estrictamente consecutivas. En dicha "edad 1,5" podemos encontrar conceptos que escapan tanto a la tiranía de la composición a gran escala -ya sea en su versión beauxartiana, o en su versión funcionalista-, como también a la noción ilustrada por Godard en Deux ou trois choses que je sais d'elle. Una de estas alternativas fue aquella concebida por Gaston Bardet (1907-1989), un urbanista apasionado y crítico furibundo de los modernos -muy cercano del historiador Marcel Poëte (1866-1950) de quien fuera su exégeta además de su yerno-, que optaba por una convergencia entre la morfología social y la morfología urbana. La teoría de los "escalones" propuesta por Bardet permitía pensar la ciudad no solo como un ensamblaje de edificios, sino también como una combinación de colectividades que comparten los recursos de una aglomeración ${ }^{56}$ (Figura 27).

Aunque Bardet se interesó fundamentalmente por la dimensión social del urbanismo, la noción de arquitectura "urbana" -utilizada también por Pierre Lavedan (1885-1982) en su Histoire de l'urbanisme para designar únicamente los conjuntos coherentes construidos en las villes nouve$1 / e s^{57}$ - fue por entonces otro concepto que logró sintetizar las esperanzas de quienes imaginaban poder reencontrar de alguna manera la complejidad de la ciudad histórica. Un caso distinto lo constituyeron más tarde Aldo Rossi y sus colegas, para quienes el urbanismo era ante todo una aspiración, una cualidad real que la arquitectura podía recuperar siempre y cuando se fundase en el estudio riguroso de las ciudades históricas con el fin de

56 Ver Le Nouvel Urbanisme (Bardet, 1948). Sobre este personaje controversial, ver mi artículo titulado "Le 'nouvel urbanisme' de Gaston Bardet", publicado en Le Visiteur (1996, pp. 134-147).

57 Ver Qu'est-ce que l'urbanisme? (Lavedan, 1926, pp. 6-7). 
• Figura 23. Representación de la plaza de un antiguo poblado

Fuente: Raymond Unwin (1909).
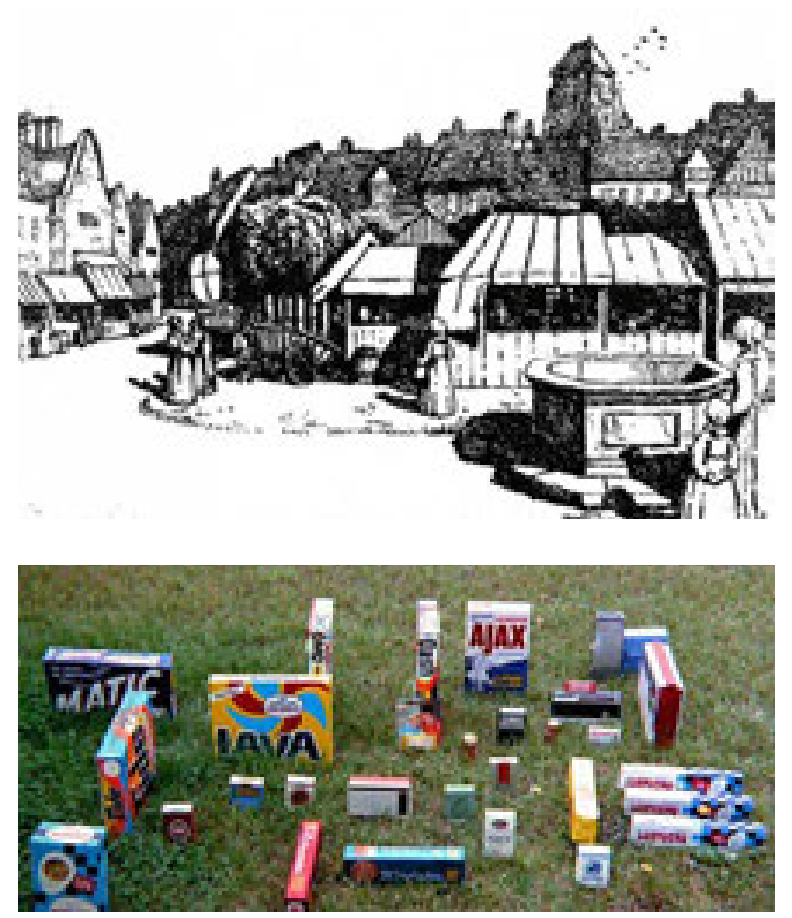

(A) Figura 24. Fotograma de la escena final de Deux ou trois choses que je sais d'elle (1967), de Jean-Luc Godard, en la cual los empaques de diversos productos de consumo (jabones, cigarrillos, etc.) reconstituyen formas conocidas en los grands ensembles construidos durante aquellos años en la periferia de París

Fuente: Godard (1967).

extraer de allí los rasgos específicos e interpretarlos adecuadamente.

\section{Conclusión: sobre el narcisismo de la arquitectura}

La relación entre el edificio, la ciudad y el paisaje es uno de los grandes temas que ha enfrentado entre sí a las diversas corrientes de la arquitectura contemporánea. Hace ya un cuarto de siglo, en su célebre y no menos incomprendido $S, M, L, X L$, Rem Koolhaas criticaba los grandes edificios autosuficientes señalando -sin estar de acuerdo con esto, como se le suele reprochar- que el eslogan "Fuck context!" resume la idea en torno a la cual se congregan todas aqueIlas nuevas y enormes edificaciones (Koolhaas y Mau, 1995, p. 495). La triple torre proyectada por Koolhaas, que fue inaugurada en 2014 en Rotterdam, revela hasta qué punto la posición del controvertido arquitecto holandés es mucho más compleja que cualquier eslogan, y busca justamente crear un contexto en un lugar desgarrado por numerosas intervenciones puntuales. En la punta de una isla salpicada de rascacielos -retomo aquí la imagen de Manhattan que Henry James describió desde la bahía cuando regresaba a New York en 1904-, la triple torre de Koolhaas logra conformar un entorno con sus vecinos, los cuales, a pesar de su yuxtaposición, no constituían hasta entonces un auténtico paisaje metropolitano (Figura 28).

En el otro extremo encontramos el interés con el que otros arquitectos se han esforzado por encontrar las huellas y los vestigios -a menudo tan tenues- de una historicidad de los lugares, cuya interpretación poética pueda servir de base a sus propios proyectos: estos adeptos se sitúan en las antípodas de cualquier política de tabula rasa, a la cual sí se habían resignado sus predecesores durante la segunda posguerra.

En 2009, Marc Augé (1935-) un explorador elocuente de los denominados "non-lieux" (los no lugares) de la ciudad contemporánea, publicó en el diario Le Monde una columna sobre la "arquitectura global" en la cual manifestaba su deseo de que los arquitectos: "réussissent à s'affranchir de la culture du 'projet', cette forme de pensée au 'coup par coup' imposée par l'idéologie de la consommation, pour rester ou redevenir des visionnaires du monde" (Augé, 2009) ${ }^{58}$.

Augé, prisionero curiosamente de una idea dominante que circunscribe la arquitectura a los grandes gestos a menudo kitsch de las vedettes de la sociedad mundial del espectáculo -a quienes Charles Jencks (1939-) califica como "icónicos"59-, reencontraba el tono de Bataille, y olvidaba de paso la energía desplegada por decenas de miles de arquitectos que practican dicha cultura del proyecto aunque aplicada a programas prosaicos: no es en los nuevos templos de la sociedad contemporánea -aeropuertos, óperas o muesos- en donde los arquitectos imprimen dicha cultura, sino en la vivienda, las escuelas y los equipamientos colectivos buscando con ello lo que Zola (1886) denominó en su momento la "fórmula arquitectónica de [la] democracia" (cuando el escritor invitó en 1886 a los arquitectos a abandonar "las por siempre empobrecidas combinaciones hechas de piedra" para mejor "buscar las formas monumentales derivadas de las propiedades del hierro"). A la par con la representación de los poderes -políticos o económicos-, la arquitectura modela el marco cotidiano de las políticas sociales: conferirle una calidad espacial y estética no entra en contradicción con las formas de uso de las cuales es objeto, por el contrario, es gracias a la transposición poética de tales usos que la arquitectura puede ofrecer en el presente lo mejor de ella, como elemento activo de toda política.

Para comprender los ciclos según los cuales la arquitectura se ha transformado, puede resultar más útil -antes que poner en práctica los métodos históricos que la consideran como un ámbito hermético-, inscribirla plenamente en la historia, teniendo en cuenta las necesarias continuidades relativas a duraciones, crisis y rupturas. Múltiples en su naturaleza, los materiales de esta historia son orales, archivísticos, escritos, aunque los primeros documentos sean los edificios en sí mismos, en su relación con los discursos que los han generado y acompañado. Como lo ha recordado Anthony Vidler ${ }^{60}$, Siegfried Kracauer presentó en

58 "...lograran liberarse de la cultura del 'proyecto' - esa forma de pensamiento del 'según el caso' impuesta por la ideología consumista-, para que de esa manera pudieran volver a ser verdaderos visionarios"

59 Ver The Iconic Building, the Power of Enigma (Jencks, 2005). 60 Ver Histories of the Immediate Present: Inventing Architectural Modernism (Vidler, 2008). 
1969 en L'Histoire. Des avant-dernières choses la investigación histórica como una navegación realizada entre dos tipos de visión que Kracauer comparaba con los planos cinematográficos: el plano general y el primer plano. El primero de ellos permitiría apreciar las estructuras de conjunto de una macrohistoria, mientras que el segundo tipo permitiría descubrir, a una escala microscópica, los destinos y las experiencias humanas (1969, p. 169). Desde mi punto de vista, la historia de la arquitectura requiere de una navegación constante entre estos dos tipos de visión: la que se ocupa de los conjuntos urbanos, que da cuenta de las políticas sociales o técnicas, y aquella que se ocupa de los edificios o de sus interiores, para dar cuenta de los ideales y compromisos tanto de sus creadores como de sus habitantes.

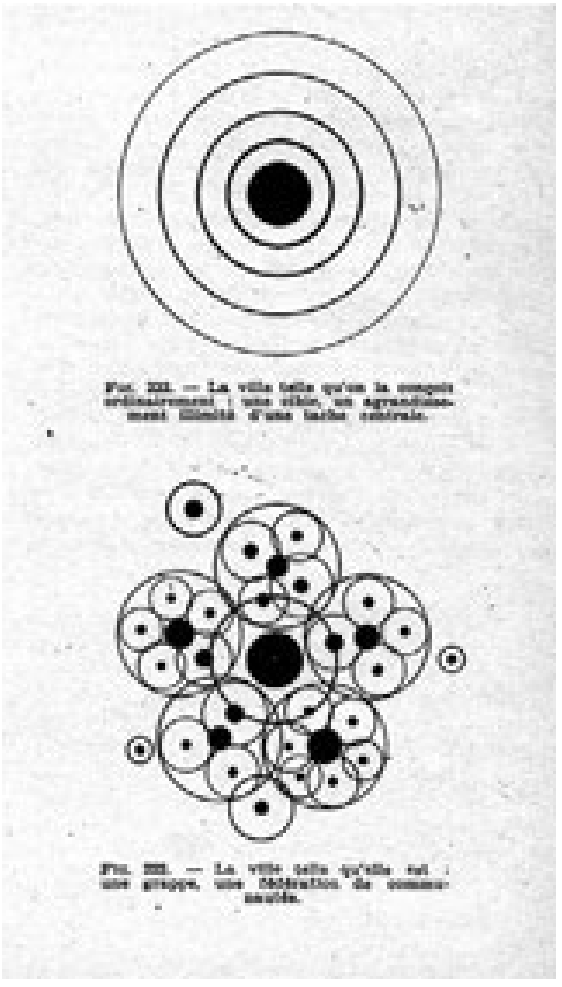

(A) Figura 27. "La ville, grappe plutôt que cible": ilustraciones para explicar la visión ideal de la ciudad (arriba), frente a la realidad más compleja de su estructura como federación de comunidades que se entrecruzan Fuente: Bardet (1945).
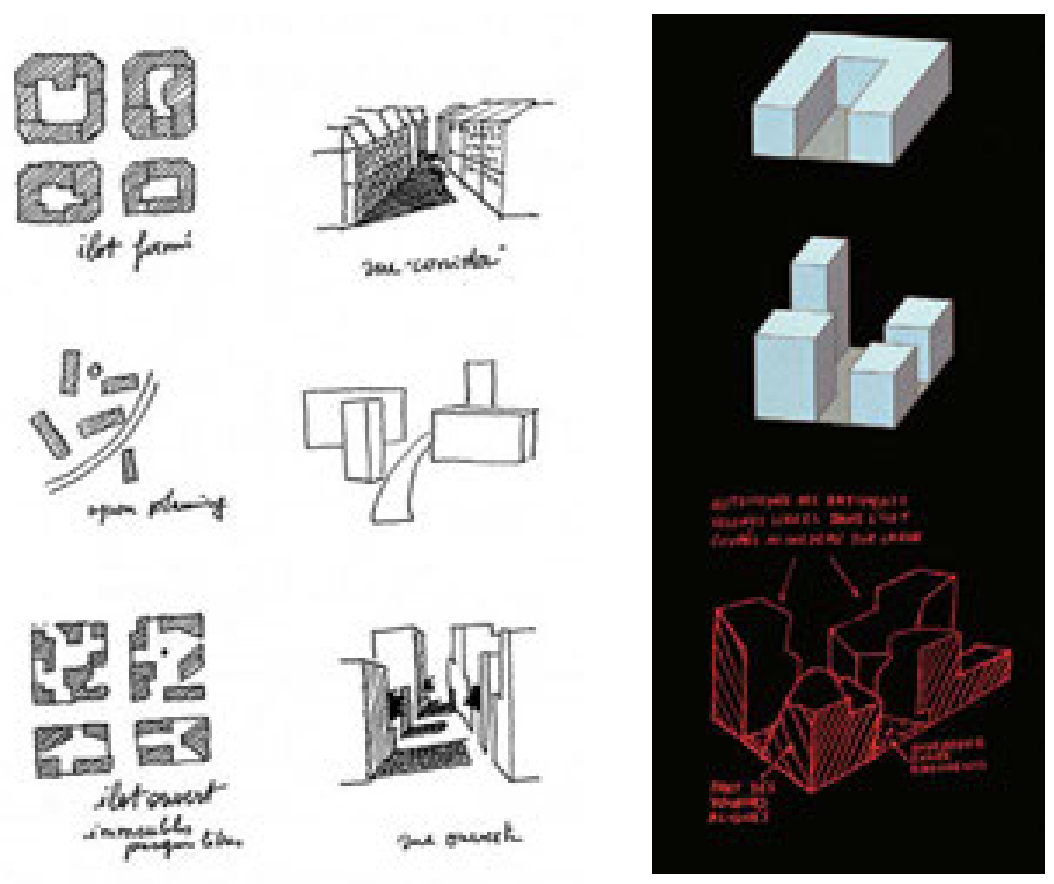

(A) Figuras 25 y 26. Croquis sobre el concepto de "îlot ouvert" de Portzamparc, aplicado particularmente en el proyecto para el sector Massena (1995-2012) en París

Fuente: (C)Atelier de Christian de Portzamparc*.

* París, quartier Massena, en http://www.christiandeportzamparc.com/fr/ projects/quartier-massena/

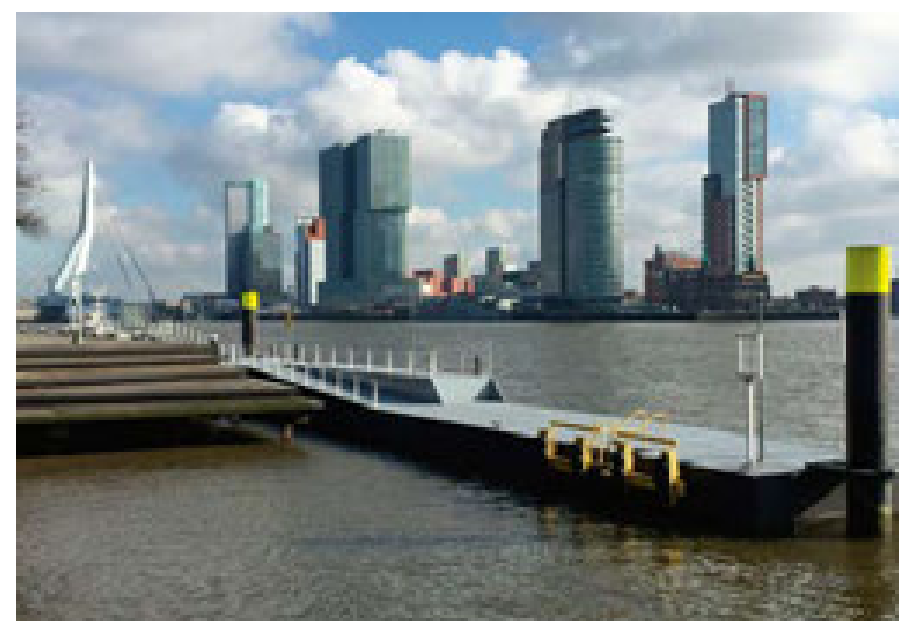

(A Figura 28. Vista desde la ribera norte del río Maas: centro izquierda se aprecia el proyecto "De Rotterdam" concebido por Rem Koolhaas y la Office for Metropolitan Architecture (OMA)

Fuente: fotografía de Jean-Louis Cohen. CC BY-NC-ND.

\section{Referencias}

Rubio, E. y Tsiomis, Y. (dirs.) (2016). Architecte à la plume. Paris: Éditions de La Villette.

Andreu, P. (2014). Enfin: roman. Paris: Gallimard.

Augé, M. (2009). L'architecture globale. Le Monde, 18-19 octobre. Recuperado de https://www. lemonde.fr/idees/article/2009/10/17/marc-auge-l-architecture-globale 12552523232. html

Bardet, G. (1945). Pierre sur pierre. Construction du nouvel urbanisme. Paris: Éd. LCB.

Bardet, G. (1948). Le Nouvel Urbanisme. Paris: Vincent \& Fréal.

Barré, V., Berger, P. et al. (1981). Panauti, une ville au Népal. Paris: Berger-Levrault.

Barthes, R. (1973). Le Plaisir du texte. Paris: Seuil.

Barthes, R. (1957). Mythologies. Paris: Seuil.
Bataille, G. (1929, mars). Architecture, Documents, 2.

Bonnier, L. (1903). Les Règlements de voirie. Paris: Charles Schmid.

Boudon, P. (1969). Pessac de Le Corbusier. Paris: Dunod.

Boudon, P. (1992). Introduction à I'architecturologie. Paris: Dunod.

Cacciari, M. (1973). Metropolis: Saggi sulla grande città di Sombart, Endell, Scheffler e Simmel. Roma: Officina Edizioni.

Candilis, G. (1977). Bâtir la vie. Paris: Stock.

Choay, F. (1965). L'Urbanisme, utopies et réalités; une anthologie. Paris: Seuil.

Chung, Ch. J., Inaba, J., Koolhaas, R. y Leong, S. T. (2001). Great Leap Forward. Colonia: Taschen / Cambridge, Mass.: Harvard Design School.
Cohen, J-L. (2017) Architecture, modernité, modernisation. Paris: Collège de France/Fayard. Recuperado de https://books.openedition. org/cdf/4864

Cohen, J-L. (2015). La Coupure entre architectes et intellectuels, ou les enseignements de l'italophilie. Bruselas: Mardaga [edición revisada de la publicación original de 1984].

Cohen, J-L. (2014). L'Architecture au XXe siècle en France; modernité et continuité. Paris: Hazan.

Cohen, J-L. (2014). Modernité et internationalisation. Revue de l'art, 186, 37-43.

Cohen, J-L. (2011). Architecture en uniforme. Projeter et construire pour la Seconde Guerre Mondiale. Paris: Hazan. 
Cohen, J.-L. (2007). Introduction. En Le Corbusier, Toward an Architecture (pp. 5-82). Los Angeles: Getty Research Institute.

Cohen, J-L. (2005). Des mains qui voient: les cours du CNAM (1958-1971). En C. Dumon d'Ayot, y B. Reichlin (dirs.), Jean Prouvé. Poétique de l'objet technique (pp. 50-55). Weyl/ Rhein: Vitra Design Museum

Cohen, J-L. (2004). Le culture della modernizzazione: il balletto delle egemonie. En M. L. Scalvini y F. Mangone (dirs.), Immagini e temi. del Dizionario dell'architettura del XX secolo (volumen temático, pp. 21-31). Roma: Istituto della Enciclopedia italiana.

Cohen, J-L. (1996). Le "nouvel urbanisme" de Gaston Bardet. Le Visiteur, 2, 134-147.

Compagnon, A. (1990). Les cinq paradoxes de la modernité. Paris: Seuil.

Damisch, H. (1972). Théorie du nuage. Pour une histoire de la peinture. Paris: Seuil.

Damisch, H. (1996). Skyline. La ville Narcisse. Paris: Seuil.

De Biasi, P.-M. (2000). Pour une approche génétique de l'architecture. Genesis, 14, 13-65. Recuperado de https://www.persee.fr/doc/ item 1167-5101 2000 num 1411134

Devillers, C. (1981). Le Creusot: naissance et développement d'une ville industrielle, 1782-1914. Seyssel: Champ Vallon, colección "Milieux".

Drexler, A. (dir.) (1977). The Architecture of the École des beaux-arts. London: Secker \& Warburg.

Dufau, P. (1989). Un architecte qui voulait être architecte. Paris: Londreys.

Eco, U. (1982). Préface. En V. Gregotti, Le territoire de l'architecture. Paris: L'Équerre.

Epron, J-P. (1997). Comprendre l'éclectisme. Paris: Norma.

Filippi, P. (1939, octobre-novembre). Le marché couvert de Clichy (Seine). La Technique des Travaux, 4, pp. 518-528.

Foucault, M. (1984). Des espaces autres. Architecture, mouvement, continuité, 5, octubre, pp. 46-49. [conferencia pronunciada en el Cercle d'études architecturales, el 14 de marzo de 1967].

Fraisse, L. (2003). Émile Mâle et le secret perdu de la Recherche. En Marcel Proust aujourd'hu (pp. 9-34). Amsterdam: Rodopi.

Freigang, C. (2002). Sources et prémices de l'édifice théorique. En J. Abram, J-L Cohen y G. Lambert (dirs.), Encyclopédie Perret (pp. 156159). Paris: Monum, Éditions du Patrimoine, IFA/Institut français d'architecture, Le Moniteur.

Giedion, S. (1928 [2000]). Bauen in Frankreich Eisen, Eisenbeton. Berlin, Leipzig: Klinkhardt \& Biermann [traducción francesa: Construire en France, en fer, en béton. Paris: Éditions de la Villette].

Godard, J-L. (1967). Deux ou trois choses que je sais d'elle. En M. Cardinal, Cet été-là. Paris: Julliard Argos Films. [Film] Recuperado de https://www.youtube.com/watch?v=0alzi8lz$\mathrm{mCQ}$

Gregotti, V. (1966). Il territorio dell'architettura Milano: Feltrinelli Editore [traducción francesa: Le Territoire de l'architecture. Paris: Éditions de l'Équerre, 1982].

Guiheux, A. y Cinqualbre, O. (dirs.) (1990). Tony Garnier, l'œuvre complète. Paris: Centre Pompidou.

Heidegger, M. (1952). Bauen, wohnen, denken. En O. Bartning (dir.), Mensch und Raum, Darm städter, Gespräch (pp. 72-88). Darmstadt: Neue Darmstädter Verlagsanstalt.
Hitchcock, H.-R. y Johnson, P. (1932). The International Style: Architecture since 1922. New York: W.W. Norton \& Co. [traducción francesa: Le Style international. Marsella: Parenthèses, 2001].

Hugo, V. (1831). Notre-Dame de Paris (2 vols. 3 ed.). Paris: Charles Gosselin. Recuperado de https://gallica.bnf.fr/ark:/12148/bpt6k6497803t?rk=42918;4

Hugo, V. (1865). Notre-Dame de Paris (1 vol.) Paris: J. Hetzel et A. Lacroix Éditeurs. Recuperado de https://gallica.bnf.fr/ark:/12148/ bpt6k9742207t?rk=21459;

Huet, B. (1984). La città come spazio abitabile, alternative alla Carta di Atene. Lotus, 41, 6-17.

Ingersoll, R. (1995). Entrevista a Manfredo Tafuri, en "Il progetto storico di Manfredo Tafuri". Casabella, 619-620.

Jencks, Ch. (2005). The Iconic Building, the Power of Enigma. New York: Rizzoli.

Jourdain, F. (1893). Dédicace. En L'Atelier Chantorel. Paris: G. Charpentier et E. Fasquelle.

Koolhaas, R. y Mau, B. (1995). S, M, L, XL. New York: Monacelli Press.

Koolhaas, R. (1978). Delirious New York. Oxford: Oxford University Press (traducción francesa: New York délire: un manifeste rétroactif pour Manhattan. Paris: Éditions du Chêne, 1978].

Kopp, A. (1967). Ville et révolution; architecture et urbanisme soviétiques des années vingt. Paris: Anthropos.

Kostka, A. y Wohlfarth, I. (dir.) (1999). Nietzsche and "An Architecture of Our Minds". Los Angeles: Getty Research Institute for the History of Art and the Humanities.

Kracauer, S. (1969). History, the Last Things Before the Last. New York: Oxford University Press (traducción francesa: L'Histoire. Des avant-dernières choses. Paris: Stock, 2006).

L'Architecture d'aujourd'hui, 249, febrero 1987 (número especial: "Corbu").

Lavedan, P. (1926). Qu'est-ce que l'urbanisme? Paris: Laurens.

Le Corbusier (1960). L'Atelier de la recherche patiente. Paris: Vincent \& Fréal.

Lengereau, E. (2001). L'État et l'architecture: 1958 1981: une politique publique? Paris: Picard.

Lods, M. (1976). Le Métier d'architecte: entretiens avec Hervé Le Boterf. Paris: France-Empire.

Loos, A. (1979 [1910]). Architecture. En Paroles dans le vide. Paris: Champ libre.

Maak, N. (2010). Der Architekt am Strand. Le Corbusier und das Geheimnis der Seeschnecke. Munich: Carl Hanser Verlag.

Marin, L. (1973). Utopiques, jeux d'espace. Paris: Minuit.

Meyer, A. G. (1907). Eisenbauten, ihre Geschichte und Æsthetik. Esslingen: Paul Neff Verlag (traducción francesa: Construire en fer: histoire et esthétique. Gollion: Infolio, 2005).

Moneo, J. R. (2004). La solitudine degli edifici e altri scritti. Turin: Umberto Allemandi.

Moneo, R. (1978). On typology. Oppositions, 13 23-45.

Neumeyer, F. (1996). Mies van der Rohe. Réflexions sur l'art de bâtir. Paris: Le Moniteur.

Parent, M. (1999). Paul Valéry et l'architecture: les paradoxes d'Eupalinos. En M. Bertaud (dir.) Architectes et architecture dans la littérature française. Boulogne: Association pour la diffusion de la recherche littéraire.

Pommier, J. (2010). Vers une architecture urbaine, la trajectoire de Bernard Huet. Tesis doctoral, Université Paris 8.

Pouillon, F. (1968). Mémoires d'un architecte. Paris: Seuil.
Prigge, W. (dir.) (1999). Ernst Neufert: normierte Baukultur im-20. Jahrhundert. Francfort-sure-Main: Campus-Verlag.

Reichlin, B. (1985, diciembre). Maison du peuple at Clichy, a masterpiece of "synthetic" functionalism? Daidalos, 18, 88-99.

Reichlin, B. (2013). Dalla "soluzione elegante" all' "edificio aperto". Scritti attorno ad alcune opere di Le Corbusier. Mendrisio: Mendrisio Academy Press.

Reichlin, B. (2013), Una sfida al sistema architettonico della tradizione. II padiglione Church a Ville d'Avray. En B. Reichlin, Dalla "soluzione elegante" all' "edificio aperto". Scritti attorno ad alcune opere di Le Corbusier (pp. 207 233). Mendrisio: Mendrisio Academy Press.

Rossi, A. (1966). L'architettura della città. Padova: Marsilio Editori (traducción francesa: L'architecture de la ville. Paris: Éditions de l'Équerre, 1981).

Ruskin, J. (1904). La Bible d'Amiens (traducción, notas y prefacio por Marcel Proust). Paris: Société du Mercure de France. Recuperado de https://gallica.bnf.fr/ark:/12148/ bpt6k97739274?rk =21459;2

Tafuri, M. (1968). Teorie e storia dell'architettura traducción francesa: Théories et histoire de I'architecture. Paris: SADG, 1976)

Unwin, R. (1909). Town Planning in Practice. An Introduction to the Art of Designing Cities and Suburbs. London: T. Fisher Unwin (traducción rancesa: L'Étude pratique des plans de villes. Paris: Librairie centrale des beaux-arts, 1922). Recuperado de https://archive.org/details/ townplanninginp00unwigoog/page/n11

Vago, P. (2000). Une vie intense. Bruselas: Archives D'architecture Moderne.

Valéry, P. (1831). Paul Valéry. Eupalinos ou l'Architecte (manuscrito autografiado). Recuperado de https://gallica.bnf.fr/ ark:/12148/btv1b53157079c.r=eupalinos\%20ou\%20l\%27architecte\%20paul\%20 val\%C3\%A9ry?rk=21459;2

Valéry, P. (1960 [1926]). Les deux vertus d'un livre. Pièces sur l'art, OEuvres II. Paris: Gallimard.

Valéry, P. (1957 [1891]). Paradoxe sur l'architecte, L'Ermitage, 3, mars 1891. En OEuvres II. Paris: Gallimard.

Venturi, R. (1966). Complexity and contradiction in architecture New York: The Museum of Modern Art (traducción francesa: De l'ambiguïté en architecture. Paris: Dunod / Bordas, 1976).

Vidler, A. (2008). Histories of the Immediate Present: Inventing Architectural Modernism. Cambridge, Mass.: MIT Press.

Vidler, A. (1976). The third typology. Oppositions, $7,1-4$

Violeau, J-L. (2005). Les Architectes et Mai 68 Paris: Éditions Recherches.

Virilio, P. (1975). Bunker archéologie. Paris: Centre Georges Pompidou.

Zevi, B. (1949). Dalla cultura architettonica. Metron, 31-32

Zola, E. (1886). L'OEuvre. Paris: G. Charpentier \& Cie. 



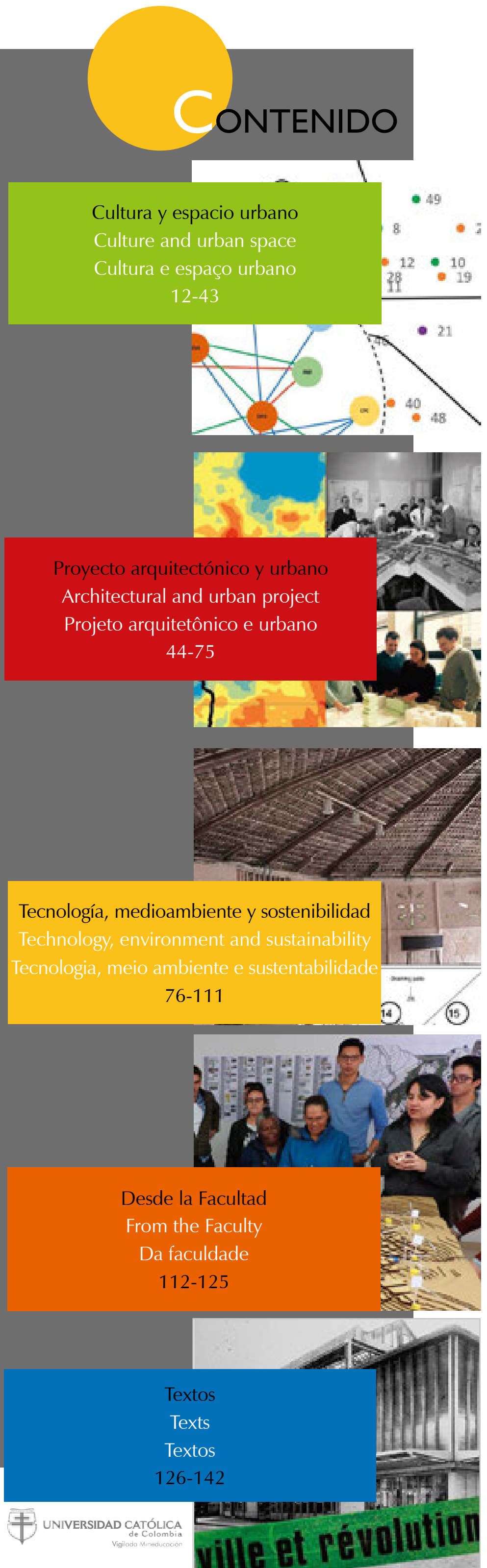

Arquitecturas colectivas y participación como estrategias para la construcción de la ciudad latinoamericana

Myriam Stella Díaz-Osorio

Pág. 3

ES

La caminabilidad en Bogotá: propósitos y condiciones socioespaciales que facilitan y limitan esta experiencia Pablo Páramo

Andrea Burbano

Pág. 12

ES EN

Planificación comunitaria en barrios socialmente

vulnerables. Identificación de los actores sociales en una comunidad

Rafael Alejandro Tavares-Martínez

Jesús Manuel Fitch-Osuna

Pág. 22

ES

Desvanecimiento de la frontera como límite. Imaginario del borde como espacio público físico y virtual

Gabriela Eloísa Muñoz-Torres

Susana Gutiérrez-Luna

Pág. 33

Estudiantes latinoamericanos en el Institut

d'Urbanisme de l'Université de Paris (1923-1941)

$$
\text { Andrés Ávila-Gómez Pág. } 44
$$

ES

Apuntes para el repensamiento de la enseñanza de la Arquitectura. La cuestión epistemológica y la necesidad de una razón ampliada
Juan J. Álvarez-Álvarez
Pág. 57

ES

Equipamientos colectivos: "lugares" de producción de capital social
José Mario Mayorga-Henao
Pág. 68
ES
Bucle multidisciplinar para la sustentabilidad urbana

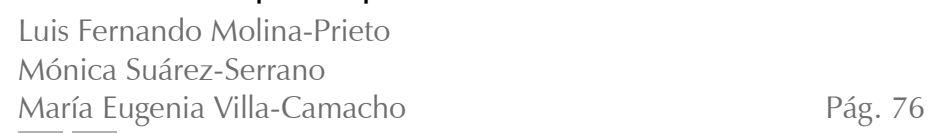

Durabilidad de los materiales naturales de construcción: percepciones de proyectistas, constructores y usuarios en Florianópolis, Brasil

Andrea Salomé Jaramillo-Benavides
Zuleica Maria Patricio-Karnopp
Lisiane Ilha-Librelotto

Pág. 89

ES

Thermal comfort in buildings for wet processing of coffee

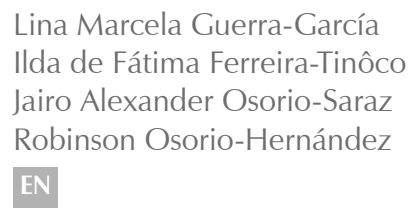

La arquitectura en los barrios: puntos de encuentro entre la academia y el saber popular

Hernando Carvajalino-Bayona

Pág. 112 ES

Arquitectura, modernidad, modernización

$$
\begin{aligned}
& \text { Jean-Louis Cohen } \\
& \text { Traductores } \\
& \text { Andrés Ávila-Gómez. } 126 \\
& \text { Diana Carolina Ruiz } \\
& \text { ES }
\end{aligned}
$$


Arquitecturas colectivas y participación como estrategias para la

Arquiteturas coletivas e participação como estratégias para construir a cidad latino-americana

\section{Stella Díaz-Osorio}

La caminabilidad en Bogotá: propósitos y condiciones socioespaciales que facilitan y limitan esta experiencia

The Walkability of Bogotá: purposes and socio-spatial conditions that facilitate and limit this experience

A caminhabilidade em Bogotá: propósitos e condições socioespaciais que facilitam e limitam essa experiência

\section{Andrea Burbano}

Planificación comunitaria en barrios socialmente vulnerables.

Identificación de los actores sociales en una comunidad

Community planning in socially vulnerable neighborhoods.

Identification of social actors in a community

Planejamento comunitário em bairros socialmente vulneráveis.

Identificação dos atores sociais em uma comunidade

Rafael Alejandro Tavares-Martinez

esús Manuel Fitch-Osuna

Desvanecimiento de la frontera como límite. Imaginario del borde como espacio público físico y virtual

$m$

这 Durabilidad de los materiales naturales de construcción: percepcione
de proyectistas, constructores y usuarios en Florianópolis, Brasil

Durability of natural building materials: Perceptions of designers, builders, and users in Florianópolis, Brazil

Durabilidade dos materiais naturais de construção: percepções de projetistas, construtores e usuários em Florianópolis, Brasil

\section{Andrea Salomé Jaramillo-Benavides}

isiane Illha-Librelotto

Thermal comfort in buildings for wet processing of coffee

\section{Confort térmico en edificaciones para procesamiento húmedo de café}

这

\section{Conforto térmico em instalações para processamento úmido de café \\ Illda de Fátima Ferreira-Tinôco}

Jairo Alexander Osorio-Saraz

Robinson Osorio-Hernandez

La arquitectura en los barrios: puntos de encuentro entre la academia y el saber popular

Architecture in neighborhoods: meeting points between academia and popular knowledge

A arquitetura nos bairros: pontos de encontro entre a academia e o saber popular Hernando Carvajalino-Bayona

\section{Arquitectura, modernidad, modernización}

Architecture, modernity, modernization

Arquitetura, modernidade, modernização
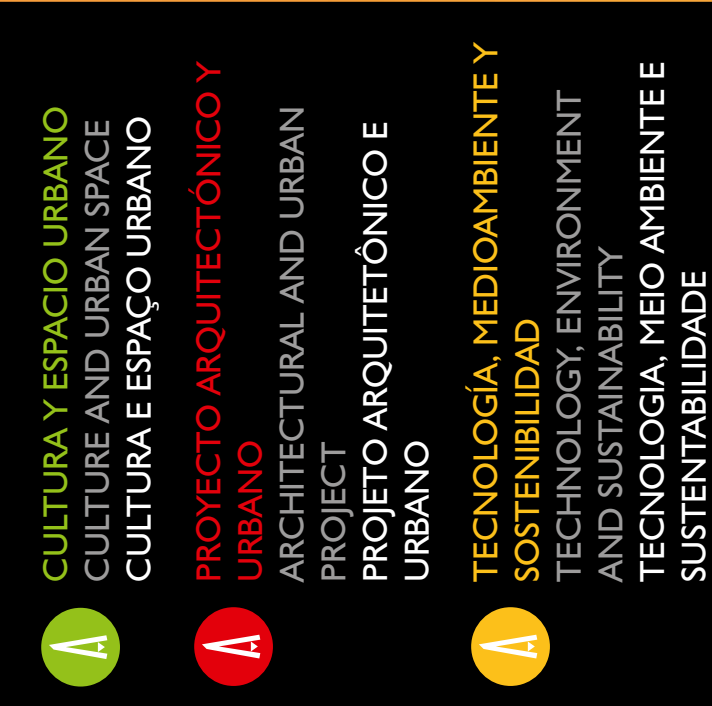

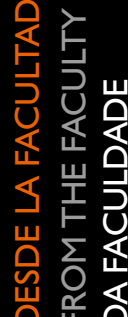

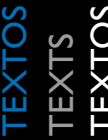
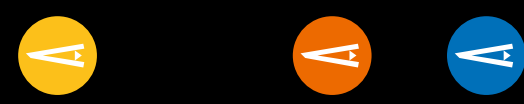

O clarivat

publind

Oarivate

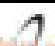
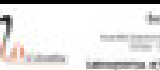

\section{RED}

REDIB

EBSCO

da

wingis
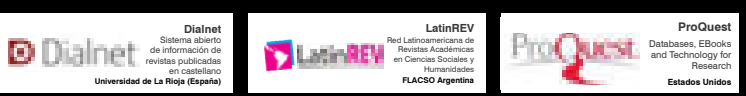

mIคR

8.syos:

Google

ARLA

ff Revista de Arquitectura (Bogotá) Universidad Catolica de Colombia

\section{¿arearauciatolica}

\$2. https://nww.mendeley.com/profles/revista-de-arquitectura-bogot/
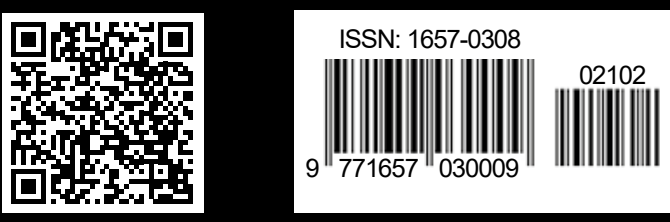